\title{
MIND THE GAP \\ EXPLORING THE EXPERIENCES OF DIASPORIC MEDIA PRODUCERS AND \\ REPRESENTATIONS OF CULTURAL DIVERSITY IN CANADA \\ by
}

Paul De Silva

A dissertation presented to Ryerson University

\author{
in partial fulfillment of the \\ requirements for the degree of \\ Doctor of Philosophy \\ in the Program of
}

Communication and Culture.

Toronto, Ontario, Canada, 2018

(C) Paul De Silva 2018 


\section{AUTHOR'S DECLARATION FOR ELECTRONIC SUBMISSION OF A DISSERTATION}

I hereby declare that I am the sole author of this dissertation. This is a true copy of the dissertation, including any required final revisions, as accepted by my examiners.

I authorize Ryerson University to lend this dissertation to other institutions or individuals for the purpose of scholarly research. I further authorize Ryerson University to reproduce this dissertation by photocopying or by other means, in total or in part, at the request of other institutions or individuals for the purpose of scholarly research.

I understand that my dissertation may be made electronically available to the public. 


\author{
Abstract \\ CULTURAL DIVERSITY IN NARRATIVE SCREEN MEDIA IN CANADA: \\ LEGISLATIVE INTENTIONS AND CURRENT REALITIES FOR SCREEN MEDIA \\ ARTISTS FROM DIASPORIC COMMUNITIES OF COLOUR. WHY THE GAP? \\ Paul De Silva \\ Doctor of Philosophy \\ Communication and Culture \\ Ryerson University \\ Toronto, Ontario, Canada, 2018
}

Prime-time narrative is the most watched and influential genre of television. It creates a sense of belonging and contributes to identity formation. It also receives the largest amount of publicly mandated funding in the form of investment, subsidies, and tax incentives in Canada. Anecdotal and empirical evidence suggests that despite legislation requiring equitable representation in all aspects of screen media, and over thirty years of many "special initiatives" and training and mentorship programs, little progress has been made in the area of equitable representation in narrative programming. This dissertation investigates the representation of diasporic people of colour in the screen-media industry in Canada. In particular, it studies how "authentic voices" from these communities are finding expression in the area of prime-time television narrative programming (scripted comedy and drama) and feature films, which ultimately find their largest audiences in broadcast screen platforms on television and increasingly via the Internet. The focus is on the legislative frameworks pertaining to the reflection of "diasporic communities of colour" in the production of screen media, specifically for prime-time broadcast in narrative, or 
what is referred to in the industry as "scripted programming," as well as on the current realities faced by creators of screen media from diasporic communities of colour in telling their stories in this arena. Through a case study of the television series Little Mosque on the Prairie, it examines the issues that affect the expression of "authentic voice" from individuals who have had the opportunity to work in the area of narrative screen media in the Canadian Broadcasting Corporation, Canada's public broadcaster, which has as one of its key priorities the reflection of the cultural diversity of Canada. The issues involved in the production of feature films by diasporic people of colour is examined through a case study of the film Heaven on Earth, written and directed by Indo-Canadian filmmaker Deepa Mehta. Mehta's film presents a unique situation in which the filmmaker, due to the previous international success of her film Water, was able to access the financial resources to produce the film in Canada and maintain her "authentic voice" without mediation in the production from external players. Part of this case study includes a documentary film featuring an interview with Deepa Mehta conducted in 2017 about her film Heaven on Earth. 


\section{Acknowledgements}

I would like to acknowledge the tremendous debt I owe to my supervisor, Dr. Lila Pine of Ryerson University for her extraordinary support over the past four years. The completion of this dissertation was made possible by her encouragement, assistance, guidance, and unfailing belief in my ability to reach my goal of successful completion of my dissertation.

I would also like to thank my committee members, Dr. Colin Moores and Dr. Allan Sears of Ryerson University for their consistent contribution of time, ideas, and expertise to this dissertation.

I would also like to acknowledge the external members of my committee, Dr. Minelle Mahtani of the University of Toronto and Dr. Pablo Idahosa of York University, whose interest and insights are greatly appreciated. A special thanks for their encouraging words, positive comments and insightful questions.

I would also like to thank Jo Ann Mackie and Dr. Jeremy Shtern and Dr. Jennifer McTavish of Ryerson University for their continued support and assistance.

Finally, I wish to acknowledge the enormous support and sacrifices made throughout my $\mathrm{PhD}$ program by my daughters Zinzi and Dominique de Silva and the tremendous support of Lawrence McNaught. 


\section{Dedication}

I dedicate this to my mother Yvonne Amelia Wrightman whose passion for the power of storytelling in all forms by all the peoples of this world and for social justice for all regardless of their origins and beliefs was my inspiration throughout this journey. 


\section{Table of Contents}

ABSTRACT III

ACKNOWLEDGEMENTS v v

$\begin{array}{lll}\text { Dedication } & \text { VI }\end{array}$

INTRODUCTION

$\begin{array}{lr}\text { WHY DIASPORA? } & 19\end{array}$

Chapter One Multicultural Policy and legislative Frameworks 23

PRODUCTION REALITIES AfFeCtING Diasporic COMMUNITIES OF COlOUR

ROLE OF THE CRTC

ETHNIC TELEVISION BROADCASTING IN CANADA

FACTORS AFFECTING REPRESENTATION

PRESENT REALITIES/SYSTEMIC BARRIERS $\quad 40$

Chapter Two The CBC—MirRor or Mask of Canada's Diversity? 4

MANDATES AND REALITIES $\quad 49$

HISTORY—FROM KING OF KENSINGTON TO KIM'S CONVENIENCE.

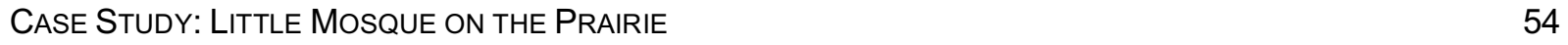

$\begin{array}{ll}\text { POLICY VS. PRACTICE } & 70\end{array}$

$\begin{array}{ll}\text { CONCLUSION } & 75\end{array}$

$\begin{array}{lll}\text { Chapter Three } & \text { an Analysis of Deepa Mehta's Heaven on Earth }\end{array}$

THE FILM $\quad 89$

$\begin{array}{lr}\text { STYLE/ PRODUCTION CONTEXT } & 94\end{array}$

$\begin{array}{ll}\text { CONCLUSION } & 98\end{array}$

$\begin{array}{lll}\text { Chapter Four } & \text { RISKS / Responsibilities / A WAY FORWARD } & 101\end{array}$

$\begin{array}{ll}\text { Works Cited ANd CONSUlted } & 112\end{array}$

POLICY DOCUMENTS 114

LIST OF INTERVIEWS $\quad 115$ 


\section{Introduction}

My dissertation is the coming together of two key themes in my personal and professional lifethat of storytelling and the quest for fairness and social justice. I was born in Calcutta, India, with Goan (Portuguese and Indian) and Bengali family ancestry.

My ancestors enjoyed a rich oral culture, resulting in a deep-rooted respect for myths and stories, still very much alive today. I credit my passion for storytelling in all forms to my great grandmother Nellie Canning-D'Costa, who in addition to being the head nurse at the Royal Medical college in Calcutta India, which by the way was highly unusual for a woman of mixed race in Colonial India, was a legendary storyteller to her family and her large circle of friends and colleagues in Calcutta. She also served as the midwife for the women in the famous Tagore family as she spoke fluent Bengali. Apparently, the stories she told them came to the great writer and humanist Rabindranath Tagore's attention. Tagore won the Nobel prize for Literature in 1913 and was knighted by Queen Victoria. He later repudiated his Knighthood in protest after the massacre by British troops of Indians who had gathered in Jallianwala Bagh in Amritsar in Punjab on April 13, 1919.

According to my mother, who would often accompany her grandmother to the Tagore family home, Tagore and my great grandmother often used to converse, no doubt about their mutual love of storytelling amongst other things, as Mr. Tagore was a man of great curiosity about all manner of things.

My great grandmother, or Burra Nana, as she was known, like many women in the Victorian era, smoked a hubbly bubbly (water pipe) or hookah while she told stories to the children at her feet. It was my mother's job to keep the coals alive. Although we can never know 
for sure, we suspect the hubbly bubbly enhanced her imagination. In any case her stories are still being told in our family. I like to think she somehow embedded a passion for storytelling in my DNA.

My mother, a storyteller in her own right, was a fierce advocate for human rights, the rights of women and people with disabilities and all people who were marginalized by society. Many of the changes she advocated for children with disabilities in the Ontario educational system have made a difference to the lives of children today. Despite the many challenges she faced as a professional immigrant woman of colour in the early 60's in Canada, she was committed to lifelong learning and effecting social change. She worked full time for several large corporations and still managed to obtain her BA and Masters of Sociology from York University's Atkinson College before she retired as a Human Rights manager at the Federal Department of Justice. She also performed in musicals with the Brampton Musical society. She had a great love for British and Hollywood movies from the Classic period which she passed on to me.

Like many immigrants who came to Canada from countries that faced major economic, social and political challenges my parents were enormously grateful to Canada for giving them a home and opportunities to live a rewarding life and raise their children in a place they saw as safe and economically, socially and politically progressive. While not ignorant and unaffected by issues of racism and marginalization they were very proud of their Canadian citizenship and believed it was their and our responsibility as children, to participate as fully as we could in the life of the country, be good citizens and help make this country better in any way that we could. 
Much of my work in screen media has been influenced by my mother's commitment to social justice issues. My concerns about the lack of representation of diasporic people of colour in the increasingly influential screen media industries are no doubt an extension of this.

My perceptions and perspectives were also influenced by the experiences and work of my wife Jennifer Hodge de Silva who was one of the pioneering Black women film makers in Canada. Her films on Aboriginal artists Bill Reid, Joe David and Dennis Highway and her groundbreaking film "Home Feeling: Struggle for Community" about the experiences of West Indian Immigrants living in Toronto's Jane Finch corridor were also about giving marginalized communities a voice.

As I outline in my dissertation, due to many factors, including the growing influence of screen media in our society, technological changes in communications and broadcasting, changing immigration patterns, and the crucial role screen media plays in creating national and personal identity and a sense of belonging, my research has revealed there is a real cause for concern about social cohesion if the issues of exclusion and marginalization are not addressed in an effective and timely manner.

My work in the screen media industry has made me increasingly aware of the rapidly changing demographics in the country, as well as the changing racial and cultural dynamics. I have become more and more interested in the role that cultural policy plays in the screen media industries in Canada and the institutional barriers that exist preventing equitable participation by people of colour in this extremely influential and important sector of the economy.

Much of my work in film and television as a journalist and producer was focused on areas related to multi-racial and multicultural issues in Canada stemming from my own 
experiences as an immigrant as well as my embodiment as a person of colour, and how I was perceived by Canadian society and decision makers in the film and television industry.

A television drama series that I conceived and produced for the CBC was centered around the idea of representing the lives of racially and culturally diverse Canadians in their own "authentic voice" in stories told through their own perceptions and experiences. This had become a concept that was increasingly important to me as I had become very aware that it was vital for people to see themselves reflected accurately and not through the mediated vision of individuals who had little knowledge of the culture and realities of the communities being portrayed. The series was called "Inside Stories" and great care was taken to preserve the "authentic voice" of the writer while ensuring the programs met the high production standards for prime-time network television. Through the production of this series and through other experiences as a producer and in my broadcast management positions I became increasingly aware of the difficulties creative people of colour working in screen media industries face in obtaining the resources required to tell their stories in a consistent and meaningful way. Being a part of the York Ryerson PhD program in Communications and Culture afforded me the opportunity to explore many of the theoretical foundations of this area as well as the cultural policies and political economy of the screen media industries and apply some perspective to much of the work I had done in my professional life.

I chose the methodology of auto-ethnography for my research using case studies of programs that I had a special interest in and some knowledge of, as it was the ideal approach given my own experiences and embodiment and the research opportunities available to me. I also wanted to augment the auto-ethnographical approach with the existing literature of research into the area of representation of racialized communities and the cultural policies relating to their 
representation, given their importance in the Canadian industrial context. I specifically wanted to investigate their stated intentions versus the realities of their implementation. This research would also hopefully identify the institutional barriers and networks of exclusion that had formed over the years which appeared to be a major impediment to the expression of "authentic voice" in screen media with its attendant implications for identity formation and social cohesion. I was greatly encouraged by many of the subjects I interviewed during my research to pursue my investigations, as they felt strongly that it was long overdue that these issues be thoroughly examined and solutions identified. Many of the people I interviewed who were from communities of colour became emotional as the subject touched on the difficult issues of race, identity, rejection and the inevitable questions concerning belonging and self-worth. I often felt emotionally drained myself after an interview. I was sustained by the hope that my research and the recommendations that might result from it could have a positive effect by identifying causes, effects on individuals and society and point the way to workable solutions.

As stated by Carolyn Ellis:

The questions most important to auto-ethnographers are: who reads our work, how are they affected by it, and how does it keep a conversation going (Ellis, Adams, Bochner, 2011).

My career has spanned television broadcasting, independent film and television production, journalism, public education, and cross-cultural communications, as well as postsecondary teaching. I am co-director of the Diaspora Film Festival. I situate myself as a member of the diasporic community of colour.

My dissertation, which includes a film about Deepa Mehta's Heaven on Earth, a paper, including a case study of the television series, Little Mosque on the Prairie, and an oral 
component, is a culmination of this experience. Combining creative and academic practices is a research method that has become known as research/creation.

My focus is not in a textual analysis of either Little Mosque on the Prairie or Heaven on Earth. My interest in these works has to do with authentic voice, present in Heaven on Earth and not so much in Little Mosque on the Prairie, for reasons I will delve into in the body of my dissertation. By offering an inside perspective, I am offering my own authentic voice.

For the written component, I have consciously attempted to write in language that will be accessible to non-academic readers, while adhering to normative writing practices for academic research. Throughout my research, many of the people I interviewed, especially those from racialized communities who were creative workers in screen media, expressed a keen interest in reading my dissertation when it was completed in order to gain a better understanding of what they identified as institutional barriers in gaining access to opportunities and resources necessary to achieve success as creators of screen media content in Canada. It is my hope that a better understanding of these factors by both the people who are affected by them and by those who are decision makers will result in positive change for screen-media creators from racialized communities.

The film gives my research activity a creative lens. It is a living example of authentic voice. Symbolically, it gives that unmediated authentic voice to Deepa Mehta in relation to Heaven on Earth. Of all the films she created, Deepa Mehta believes that Heaven on Earth was the one in which she was given complete creative control, for reasons I outline in Chapter Three and she speaks of in the film. By not including Zarqa Nawaz, the creator of Little Mosque on the Prairie, in the film component, her voice is rendered silent, as was done by the CBC by the final season of the series, for reasons I outline in Chapter Two. 
For over thirty years I worked in various sectors of the screen-based media industries in Canada. My work, both in the areas of journalism, public affairs, and documentary filmmaking as well as in narrative or scripted programming (drama, situation comedy programs) has been in some way connected to the changing racial and cultural demographics of Canada.

After completing my undergraduate degree, I was hired as a Human Rights Officer by the Ontario Human Rights Commission, which brought me into contact with many culturally diverse communities and the issues pertaining to discrimination in employment, housing, and access to public spaces. I left the Ontario Human Rights Commission to work first in Community Radio and later for the Canadian Broadcasting Corporation in a number of capacities including as a radio and television news reporter, documentary producer/director, and finally as an executive in the Drama department. I also spent a number of years as the head of an independent production company, primarily because there was a shift in the way programming was being financed, from "in house" production by broadcasters to independently produced programs commissioned by broadcasters but financed through newly created Government Crown Corporations which were funded by Parliamentary allocations. Many of the programs I worked on concerned issues relating to the growing multi-cultural community in Toronto as well as other urban areas in Canada. In some instances they were programs celebrating the diverse cultural heritages that made up the Canadian Mosaic, in others investigating the "hard issues" involving immigration, racism, economic marginalization, and crimes perpetrated by and against members of new immigrant communities. Therefore, as a member of a "visible minority" community — a term that is increasingly contested by members of these communities as well as by the United Nations Council on the Elimination of Racial Discrimination, but still used both by government and in societal contexts - I have "lived experience" in the issues involved in the participation and 
representation of "visible minority," or "racialized" or "communities of colour" in screen media in Canada.

Visible minority is defined by the Canadian government as "persons, other than Aboriginal Peoples, who are non-Caucasian in race or non-white in colour." The term is used primarily as a demographic category by Statistics Canada, in connection with Canada's Employment Equity policies. My preference is to use the term "diasporic communities of colour" as it is more accurate in today's Canada.

I chose the York/Ryerson Joint program in ComCult to pursue my PhD because it would give me the freedom to realize a multi-faceted approach. In addition to its focus on cultural policy and its effect of the production of screen media and the technology of screen media, ComCult allows for the production of creative work. While I did not know specifically what the exact focus of the film might be at the time I enrolled in the program, it was my intention, given my interest in the representation of people of colour in the production of narrative programming in Canadian screen media that it would focus on this area.

My decision to research Deepa Mehta's film Heaven on Earth afforded me the opportunity to document the unique circumstances of the production of the film and the issues concerning the industrial modes and institutional practices concerning feature film production as well as the expression of "authentic voice" of diasporic screen-media creators in the Canadian context.

As I will explain in greater detail in the case study of the film, I also wanted to bring to light the reasons for Mehta's decision to make Heaven on Earth with its strong social message concerning spousal abuse and immigrant alienation and the struggle for dignity by recent 
immigrants from South Asia, instead of pursuing the opportunity she had to write and direct a large budget film produced by a Hollywood studio.

It is my hope that producing a short film on this subject will make it more accessible to a wider audience than those who might read the written component, even though, as stated above, I have made every effort to write in an accessible way.

My research indicates that currently no film on this subject exists. That Mehta agreed to be interviewed on camera about the circumstances in which the film was created and her own creative process cemented my decision to produce a short documentary film.

While Mehta had agreed to do the interview and provide access to footage related to the production of the film (rehearsals, creative preparations with actors, etc), it was extremely difficult arranging a time in which to do the interview to fit her schedule. I also wanted to interview David Hamilton, the producer of the film (and Mehta's husband) about the financing of the film as it was an important factor that affected the expression of Mehta's authentic voice. My research had indicated that due to both the critical and financial success of her previous film, Water, she was in a much stronger position to make creative decisions without mediation from the agencies that were the primary financiers of Heaven on Earth. I was finally able to interview Mehta and Hamilton in their home in Toronto just prior to their departure for India in October of 2015. I engaged a professional cameraman to provide high-quality footage of the interview which was filmed using two Sony DSLR digital cameras, a sound recordist, and an editor using an Avid editing system to ensure a level of quality that would be suitable for distribution of the film after the completion of my dissertation.

I worked closely with the editor and my supervisor on several cuts of the film. The first assembly was approximately an hour long and it included the interview with Hamilton talking 
about aspects of the financing of the film and Dr. Shahram Tabe, a film scholar and Director of the International Diaspora Film Festival commenting on Mehta's work as an internationally acclaimed diasporic filmmaker working in a transnational film environment.

However, in screenings and discussion with my supervisor, and after receiving feedback from others not connected to my dissertation, I concluded that the film would be more impactful if Mehta's voice alone was represented in the film. It would in fact be a direct representation of her "authentic voice" on the circumstances leading to her decision to make the film and her creative process. Several further cuts were made to refine the structure and focus of the film. I decided not to add a "voice over narration" and to instead use text to provide necessary contextual information, allowing for Mehta's voice to be the only one present in the film.

It is my hope that the film will be accessible to educators and students as well as the general public who might be interested in this subject. I have already had several requests to make it available for educational purposes in courses that focus on Canadian film and on immigrant women of colour and the issues they face in Canada.

Part of my concern about the low levels of representation and participation in narrative programming in prime-time television are the implications for the diasporic communities of colour as well as for Canadian society at large. Several studies (Fleras, Kuntz, Reitz, Bannerjee, Mahtani, Karim, and Jiwani et al) have pointed to concerns relating to the effect on personal and national identity formation, levels of disassociation from mainstream society, as well as issues of employment equity and the right to participate in a major and growing sector of the Canadian economy. Studies by the Canadian Media Producers Association indicate that approximately \$3.1 billion was spent in the television and feature film independent production sector in 2016 . Approximately \$286 million was invested by the Canadian Media Fund, a crown corporation that 
receives its funding directly from the Government of Canada and levies on television broadcast distributors, namely cable and satellite distribution companies. While there are no empirical studies available indicating the participation of racialized or diasporic people of colour in this sector, partly because of issues pertaining to provisions in Canada's Privacy Act and the cost of doing these studies, anecdotal and observational evidence based on a survey of scripted programs produced by diasporic producers of colour and interviews with screen media producers from these communities indicates that this level would likely be not more than one per cent and increases slightly if a feature film made by a person of colour is included (Canada One TV CRTC application research 2007).

I was inspired and guided in my approach to my dissertation by the research done by media scholars Dr. Minelle Mahtani, Dr. Catherine Murray, Dr. Charles Davis, Dr. Jeremy Shtern, and Dr. Augie Fleras who have done extensive work in the area of minority reflection in screen media and related issues of identity formation as well as issues related to employment equity.

In her groundbreaking study Silent on the Set: Cultural diversity and race in English Canadian TV drama, which used both quantitative and qualitative research methods to examine diversity and race in screen media in Canada in 2005, Dr. Murray stated:

In an April 2001 editorial for the Toronto Star, Haroon Siddiqui called on media organizations (and the CRTC) to recognize the gap between diverse populations and their lack of representation on network television, most of which he characterized as "too anachronistic, clichéd and crude to be of much relevance to contemporary Canada" (Toronto Star, 2001). 
Faulting increased convergence and concentration of ownership for the lag in media, Siddiqui wrote:

Canada has become increasingly multi-racial and multi-coloured, yet our media haven't.... These Canadians are not reflected on media payrolls. This is not to say that hiring should duplicate the population mix, but rather that it run in rough proportion to the available talent, as in our quest for gender parity... (Toronto Star, 2001).

Murray goes on to say:

These final variables acknowledge the relationship between the invisibility of minorities in media with industry access and hiring practices. Stereotypical portrayals of minorities or their exclusion altogether is very much related to creative control and influence. In the example of news, "the broadcaster, reporter, camera person, and editor have a context that affects the way in which they interpret images, events, and situations. This context influences what they choose to film or air, what they select, and what eventually becomes part of the story (...) they are influenced by their own connections to groups and institutions that have power and influence" (Tator et al. 2000, 300). This description is also proper as it applies to the content of narrative television. Writers, producers, and directors from culturally diverse backgrounds are more likely to conceive of visible minority characters (and subsequently cast actors or actresses) in ethnic-specific or nonspecific roles that are nuanced and defiant of stereotype. A lack of 
exposure/access to different cultural groups (and indeed the myriad of subcultures which inevitably exist within any one minority culture) will typically result in the creation and perpetuation of stock ethnic characters or wholly assimilated ones (Murray 2005).

According to Dr. Murray the study has not been replicated due to a lack of financial support for a follow up study.

Minelle Mahtani stated in her study Representing Minorities: Canadian Media and

\section{Minority Identities:}

Varied research across disciplines demonstrates that minorities are regularly stereotyped in mass media. Media images can promote attitudes of tolerance and harmony, or fear and negativity. When media representations fail to represent Canada's minorities with sensitivity, the entire country suffers the consequences. Our task as researchers should be to create a "united front" against the preponderance of these stereotypical images by enhancing our current discourse analysis projects, coupled by further studies with media workers to examine the reasons lurking behind the continued proliferation of these images. Media workers need to consider and create alternative representations of minorities and it may well be our task to develop alliances with them to provoke other sorts of images...Researchers interviewed for this report have recommended routes for research through new methodological approaches that will serve as a means towards more inclusive and equitable representations of minorities in Canadian media, wherein 
minorities would no longer be marginalized but imagined as an integral part of the Canadian nation-state (Mahtani, 2001, 22)

Mahtani's perspective on the importance of media representation of minorities in entertainment programs was an important influence in my approach as research has indicated prime-time narrative programming is the most watched genre of screen media programming and an important influence in shaping societal attitudes.

She states further:

The literature review of the work on media-minority relations underscores some important omissions. Many researchers and media workers made it clear that they want to see more content analysis for a start. For example, "we would like to research into the electronic media with specific reference to Canadian entertainment programming, i.e. drama and popular entertainment shows," commented two media researchers (Mahtani 2001, 22).

Entertainment programming (primarily in the form of one-hour television drama and situation comedies) plays a key role as a societal influencer in identity formation and creating a sense of belonging.

Narrative programming is the most widely viewed and popular form of television in Canada, and a key influencer in shaping both personal and national identity, and fostering a sense of belonging in diasporic communities (Fleras and Kunz, 2001). 
According to broadcast executive and former vice-president of CBC English television, Richard Stursberg:

Television is the biggest and most important cultural medium in the world. People spend more time watching television than doing anything else ,except sleeping and working. Canadians watch an average of twenty- four to twenty- six hours per week of television a number that has not changed significantly in the past thirty years. Despite many claims to the contrary, Google, Facebook, YouTube and other websites have not overtaken television. Indeed, new media are increasingly being used to watch traditional television shows....In English Canada, the most popular television shows are-without the exception of hockey broadcasts- all entertainment based, just as they are everywhere else (Stursberg, 2012, 61)

Television entertainment programming is also the most financially lucrative sector for screenmedia workers in Canada. Additionally, I had some experience in producing this genre, having produced a number of television series as an independent producer as well as been responsible for overseeing the development and production of several narrative television programs as a broadcasting executive for the CBC and Vision TV. I decided therefore to focus my research on the area of narrative or scripted entertainment programming in screen media in Canada and how culturally diverse communities of colour are represented in the key positions of production, specifically in television and feature film; their experiences in telling their stories to mainstream audiences, and in particular their opportunities to tell their stories in their "authentic voice," and the government policies and industry practices that influence this arena. 
I also decided to use the term "diasporic communities of colour" as it refers to communities who have resettled in new countries through either immigration, or due to being exiles because of political upheavals in their home countries or refugees due to war or economic conditions or natural disasters.

Dr. Davis and Dr. Shtern have done important research at Ryerson University into the representation of visible minority writers in narrative programming in screen media in Canada as well as other research into the reflection of people of colour in Canadian media, particularly in the experiences of writers of colour working in narrative screen media. As there has been very little empirical research in this field in Canada, due to in part of the cost of conducting such research, and the limited funds available, their work is an important contribution. I was fortunate to have the opportunity to work with them on the Roundtable on Cultural Diversity in Screen media in Toronto held at Ryerson University in 2010. I quote from the Roundtable Report and Action Plan in several sections of my dissertation.

In Chapter One I will first examine the legislative frameworks and policies created by the Government of Canada through the Broadcasing Act to set the goals and objectives for broadcasting in Canada. I will also examine the history and the legislation pertaining to the cultural diversity of Canada in the Multiculturalism Act and the legislation and objectives for equitable employment practices set out in the Employment Equity Act, which guarantees equitable employment for all people in Canada. I will also examine, through existing research by academics in the field and personal interviews conducted over a period of several months primarily in Toronto, Montreal, and Ottawa with key policy makers, industry executives, and workers from diasporic communities of colour working in screen media in Canada, the production process of film and television that is unique to Canada and the realities faced by 
screen media artist of colour in gaining access to resources to tell their stories in narrative or scripted programming.

In Chapter Two I will review the Canadian Broadcasting Corporation's (CBC) history in narrative or scripted entertainment programming relating to diasporic communities of colour in Canada. This will include a case study of its television production of the series Little Mosque on the Prairie, which was broadcast by the CBC for six seasons between 2007 and 2012. The case study is based on extensive interviews I conducted with the key creative people involved in the series as well as executives at the $\mathrm{CBC}$ who were involved with the initial commissioning of the series and its production.

In Chapter Three I will examine the feature film Heaven on Earth (2008), written and directed by the internationally acclaimed Indo-Canadian filmmaker Deepa Mehta, through a written analysis of the film from both its creative aspects as well as the industrial process by which the film was made. I employ the lens of "Accented Cinema" as theorized by Dr. Hamid Naficy whose book An Accented Cinema: Exilic and Diasporic Filmmaking (2001) is a seminal text in the studies of diasporic, exilic, and postcolonial cinemas and media. I also interview Ms. Mehta and the executive producer of the film, David Hamilton.

Feature films represent a much smaller segment of the screen-media industry in Canada; however, as it is a primarily writer/director driven medium as opposed to television, where most of the important creative decisions are made by producers and television network executives, feature films can allow the writer/director greater control in many instances in the expression of "authentic voice." The case study approach offers an opportunity to also examine the realities of the financing/production modes of this genre of screen media particularly in the Canadian context. The unique circumstances of the production of Heaven on Earth and Ms. Mehta's own 
personal history as a diasporic person of colour in Canada provide an important opportunity for scholarly examination. As part of my dissertation I have also produced and directed a short documentary film as a Case Study of the production of the film outlining its genesis and the approach Mehta applied in its storytelling. The film features an interview I conducted with Ms. Mehta in 2017 at her home in Toronto and visual materials from and relating to the production of the film.

Finally, in my concluding Chapter Four, I summarize my findings through my research and offer what I feel would be some options to remedy some of the systemic barriers and challenges faced by diasporic people of colour in finding success in telling their stories in narrative screen media in Canada. The issue of the reflection of diasporic communities of colour in screen media as well as other parts of society is increasingly a subject of examination and debate in countries in the Global North, with both Indigenous communities of colour (Canada, USA, and Australia) and growing diasporic communities formed through immigration and more recently from refugees primarily from Asia, Africa, and from the Middle East, particularly in Britain and central Europe.

The establishments of SBS (Special Broadcasting Services) in Australia in 1980 and Channel Four television in Britain in 1982 were both Government sponsored attempts by those countries to address the issue of representation of minority communities in screen media in those countries and provide opportunities for new and emerging independent program producers to reach a national audience. Both have had some measure of success in these areas, although recent reports in the media and through some research studies indicate that the issue of representation of minority voices continues to be a major issue for communities of colour in both countries. Undoubtedly, the Canadian experience has many unique aspects given our history, 
location, demographics, market realities, and policy initiatives in the area of multiculturalism and cultural diversity. As a result, some creative options for addressing issues of equitable representation have emerged specifically through the policies and approaches created by the Aboriginal Peoples Television Network (APTN)

It is hoped that my research will have some value in understanding the complex dynamics of the screen media industry in Canada, particularly in the production of its most watched and influential genre, and influence policy and industry decision makers and societal change makers in creating a more equitable environment and opportunities for the expression of their "authentic voice" for storytellers from diasporic communities of colour. As well my aim is to provide some insights and possible options to communities of colour and decision makers engaged in similar struggles in other parts of the world.

\section{Why Diaspora?}

The word Diaspora has its origins in ancient Greek, which translated means a "scattering" or “dispersion." Its early and most common reference was the dispersal of the ancient Jews from Israel. Later it was also used to refer to the massive movement of slaves from Africa and of Chinese people from southern China through the coolie slave trade.

William Safran, in an article entitled Diasporas in Modern Societies: Myths of Homeland and Return (1991), outlined rules to distinguish Diasporas from migrant communities. While Safran's criteria for defining diasporic communities were based on the Jewish Diaspora; he also acknowledged that the term "Diaspora" now included communities that had moved from their homeland for reasons other than being forcibly displaced by a conquering power or internal political disruptions. 
The recent mass migrations that followed World War Two, a result of economic upheavals caused by the war, the demise of several Imperial colonial governments, and political and economic shifts, have created new diasporas, primarily in Western countries, including Europe, the Americas, and Australia.

The Diasporas created by post-war immigration were initially from Eastern Europe in the early 1900s, and later from Western Europe and the Mediterranean in the 1940s, '50s and '60s. The recent large-scale immigration to Canada has been from countries in South Asia (including India, Pakistan, Bangladesh, and Sri Lanka), South East Asia (primarily the Philippines, Taiwan, and mainland China), Africa, and South America.

These recent migrations have created what are now commonly referred to as "diasporic communities" in Canada, and have been caused by the economic conditions in the "developing" countries and the need for migrants due to falling birth rates and the need for both skilled and unskilled labour in Canada.

These immigrant communities have for the most part settled in their new country with the intention of putting down roots in their new homes and becoming citizens of Canada. The advent of the concept of "multiculturalism," where new migrant communities are encouraged to retain their ancestral culture while being citizens of their new homeland, has resulted in the creation of several hybrid cultural identities amongst people in these communities, particularly in second and third generation immigrants. These communities have a strong desire to express their experiences in their own voices within their new homes through literature, screen-based technologies, and more recently via the Internet. (Fleras and Kunz 2001).

I will examine issues involving the expression of diasporic voices of colour in Canada including access to resources by members of diasporic communities which are necessary for the 
expression of these voices in screen based media, which several media scholars including McLuhan have argued is a major influence in personal and collective identity formation as well developing a sense of belonging and inclusion in society (McLuhan 1964). I will explore the primary legislative policies and frameworks that are responsible for creating and maintaining the “opportunity structures" that affect storytelling by members of diasporic communities and the challenges faced by these storytellers in Canada. I will also investigate why these policies have to this point been largely ineffective in removing the barriers that exist due to institutional practices in the film and television industry that have resulted in the creation of exclusionary barriers that affect diasporic screen storytellers of colour.

Many of these diasporic storytellers were educated in colonial and post-colonial educational institutions, and have added their voices to discourses relating to questions of identity, cultural hybridity, race, gender, equity, and post- and neo-colonial attitudes and practices by the social, cultural, and political institutions that influence and govern our society.

Several scholars, such as Fanon (2008), Said (1994), Hall (1981), Spivak (1987), Shohat (1998), Bannerji (2000), Galbuzi (2006) have provided valuable theoretical lenses to view issues of race and colonialism and post-colonialism, and how they have affected and continue to affect issues concerning the expression of authentic and unmediated diasporic voices. While their approaches to problematizing these issues may differ in several ways in matters of causality, engagement, and resistance, they essentially agree that racism and the effects of colonialism have had, and continue to have, profound effects on virtually all aspects of society, especially those who have been subject to colonial and imperial domination through institutionalized practices of exclusion. 
Central focuses of my research are the systemic barriers that have been created for the expression of "authentic diasporic voices" in Canada. A close examination of these systemic barriers is particularly important in the Canadian context given that the primary source of support for screen based media production by necessity comes from State regulated industries and funding institutions. An inquiry into the policies and practices relating to cultural production in these arenas is crucial to our understanding of the factors that shape it.

Finally I will argue that based on my research and interviews with key government policy makers and senior executives and administrators as well as a wide variety of creative workers in screen-based media from diasporic communities of colour, and through an examination of institutional practices in screen media industries and case studies of the $\mathrm{CBC}$ television series Little Mosque on the Prairie and the feature film Heaven on Earth, that by and large, legislative frameworks and programs aimed at increasing the "diversity of voices" in screen media have been marginally effective in achieving the results they were intended to achieve. I will also argue that unless specific measures accompanied by monitoring with accountable outcomes are instituted to remedy this situation very little will change, with the resulting societal impacts, including a growing sense of alienation and disassociation from Canadian society, as argued by Fleras, Reitz, and Banerjee amongst others. 


\section{Chapter One \\ Multicultural Policy and Legislative Frameworks}

The Government of Canada has created several social and cultural policies and enacted legislation encouraging and guaranteeing access to resources for members of all communities regardless of their ethno-cultural background, based on concepts of equality, fairness, and the spirit of the Government's policy of multiculturalism and the Canadian Charter of Rights and Freedoms. These policies were designed to acknowledge the contribution of the cultures brought by these new immigrant communities to the cultural fabric of Canada.

Canada has led the way in institutionalizing notions of multiculturalism and cultural diversity through its Charter of Rights and Freedoms (1982) and The Canadian Multiculturalism Act passed by Parliament in 1988 .

The groundwork for the Multiculturalism Act was laid in 1971, when Prime Minister Pierre Trudeau announced the federal multiculturalism policy. This policy was an expansion of the idea that Canada was a plural nation, which was a result of intense lobbying by ethno-cultural groups during the public hearings of the Royal Commission on Bilingualism and Biculturalism in 1963.

The multiculturalism policy announced in 1971 set the framework for all future government policies relating to ethno-cultural communities, particularly those dealing with the arts and cultural activities. When Canada's multiculturalism policy was first introduced in 1971, the make-up of Canada was profoundly different than it is today. Census data from that year indicate that $96 \%$ of the Canadian population reported their ethnic origin as European. By 2011, only $63 \%$ of Canadians reported the same. Recent debates about "reasonable accommodation" of diverse cultures, in Quebec and increasingly in other parts of Canada where there are increasing 
numbers of immigrants of colour as well as refugees from the Middle East and Africa, have focused on the concept of multiculturalism and reignited issues of racism and xenophobia towards people from visible minority communities, which Banerjee has posited are underlying currents in Canadian society (Banerjee 2000).

As an immigrant of colour to Canada I have been a supporter of the multicultural policy and the recognition in public policy that Canada is made of many cultures and they should all be respected and considered part of the national fabric. Canada's multicultural policy was the basis for policies adopted in 1978 by Australia, and in the 1980s and '90s by a number of European countries, including the United Kingdom and the Netherlands. An international consensus was proclaimed in 1997 by the American sociologist Nathan Glazer: "We Are All Multiculturalists Now."

However, reading Neil Bissoondath's book Selling Illusions: The Cult of Multiculturalism in Canada, published in 1994, made me reconsider my uncritical support for the policy. Bissoondath, who was born in Trinidad of East Indian heritage, is a writer whose novels I admire, and was at the time the book was published one of the emerging diasporic voices in Canadian society.

Bissoondath took the position that the policy of multiculturalism divided Canadians through its focus on accentuating differences in culture. He felt that because of the policy his work was often evaluated on his status as a visible minority and his ethnic origins. He felt this stereotyped him, and he attributed this perception of him and his work to the multicultural policy.

Himani Bannerji, whose book The Dark Side of the Nation: Essays on Multiculturalism, Nationalism, and Gender published in 2000, also provided a critical feminist, Marxist, and anti- 
racist perspective on Canada's official policy of multiculturalism and drew attention to what she believed was the myth of the "two founding peoples," Anglos and Francophones, which conveniently ignored the reality of First Nations and also ignored the presence of non-European immigrants who may have had a history of being indentured (as many immigrants of South and East Asian background from the Caribbean were) and politically marginalized, and only began struggling for political enfranchisement in their new homeland. Bannerji, a Bengali-Canadian writer, sociologist, and philosopher from Kolkata, West Bengal, India is also known for her reflexive analysis of gender, race, and class through Karl Marx's concept of ideology, and activist work and poetry. Much of Bannerji's perspectives were formed through her own experience as a woman of colour and through her encounters with institutional racism in Canada, which despite its policies of multiculturalism and acceptance of "diversity," she believed marginalized people who were seen as "other." She also drew attention to what she believed were the white-supremacist undercurrents in the politics of recognition for "diversity" in Canada, which essentially sought to disguise the racist power structure through the official policy of multiculturalism.

I had had similar sentiments expressed to me by writer and academic Bharati Mukherjee, a Canadian citizen who was also born in India, who declined to be part of the television documentary program I was producing in the late ' 70 s on multiculturalism for the $\mathrm{CBC}$, as she believed her views on multiculturalism would not be popular with the Canadian public. She subsequently wrote a highly critical essay on racism in Canada, particularly towards women of colour, and left the country to live and work in the United States where she felt less marginalized and where she felt the racism she encountered was not masked by hypocritical attitudes based on a so-called acceptance of "diversity." 
Since the terrorist attacks of September 11, 2001, and the growing awareness of the effects of systemic racism present in Canadian institutions, the number of dissenting voices regarding the positive effects of the multiculturalism policy has been growing. The recent terrorist attacks in the UK and Europe, including France, the Netherlands, Spain, and Germany, have caused many to reevaluate the whole concept of official multiculturalism and its support for minority cultures.

Several US and British academic critics, including Brian Berry, Samuel Huntington, and Amartya Sen, have weighed in on the issue, and Francis Fukuyama blamed Canada for exporting an ideology promoting violence. The province of Quebec's rulings regarding the wearing of traditional head coverings for Muslim women in public places have also focused attention on these issues.

However, Jeffrey Reitz in his review of Multicultiphobia, a book by Canadian academic Phil Ryan, states:

Canadians express both pros and cons, but tend to come down on the pro side. They think multiculturalism is generally a good idea. Since the policy was introduced in 1971, successive opinion polls have shown solid majorities backing multiculturalism. Many see it as part of the national identity.

Reitz also acknowledges the growing criticism of multicultural policies both in Canada and abroad but states:

Through all this, stalwart Canada has stuck with multiculturalism. This raises a question: are we out on a limb? Multiculturalism critics may be wrong-headed at times, and some of their views poorly reasoned, 
contradictory and empirically doubtful. But they are not racists or bigots—although they may suffer from "diffuse anxiety." They have raised legitimate concerns that should be addressed. We should examine items of criticism, "acknowledging those that contain some truth, challenging those that do not." A reasoned analysis based on evidence is certainly the right direction to take.

While it is not my intention to examine the policy of multiculturalism in its broader implications in this dissertation, it is important to note that the policy is increasingly being examined critically and its assumptions are being contested in many sectors of Canadian society. Nonetheless the official support of the policy continues to be strong and it remains a key part of government policies and regulations as it pertains to screen media in Canada.

The adoption of the Canadian Charter of Rights and Freedoms (1982) affirmed Canada's commitment to the values of multiculturalism and ethnic diversity. Section 27 of the Charter states: "This Charter shall be interpreted in a manner consistent with the preservation and enhancement of the multicultural heritage of Canadians". While there were no directly stipulated cultural outcomes of section 27 , it did reinforce individual and collective rights with respect to equity and cultural diversity.

Canada's multiculturalism policy was enshrined in law under the Multiculturalism Act passed by Parliament in 1988. It was the first legislation of its kind in the world and has been emulated by other countries, most notably in post-apartheid South Africa. Ironically, South African apartheid was modelled on the Canadian reservation system (https://yvesengler.com/2013/12/10/our-shame-canada-supported-apartheid-south-africa/). 
The Employment Equity Act, Section 2 is also applicable to the issue of equitable representation of minorities in Film and Television in Canada. It states in part:

[Institutions] must achieve equality in the workplace so that no person shall be denied employment opportunities or benefits for reasons unrelated to ability and, in fulfillment of that goal, to correct the conditions of disadvantage in employment experienced by women, aboriginal peoples, persons with disabilities and members of visible minorities (1995).

Initiatives by the former Department of Canadian Heritage, including a National Forum on Diversity and Culture held in Ottawa in May 2003, raised awareness of this issue of cultural diversity in the media, in both the minority communities and in mainstream consciousness as well. A report from the Forum stated:

The Film and Television industry attempts to give Canadians the opportunity to "talk to and understand each other, to gain insights into other cultures and provides a window on the world. Canada's historyas well as its cultural, ethnic, linguistic and regional diversity—is reflected — with varying degrees of success — in films and television and contributes to a healthy national life.

A definition of the word "diversity" that is pertinent to this study is the definition used by Dr. Catherine Murray in her study Cultural Diversity and Race in English Canadian TV Drama: For many, diversity is seen widely as a mixture of terms characterized by differences and similarities. Diversity evokes images of fixed and distinct cultures that persist in states of separate being. Individuals, in 
turn are slotted into these pre-existing cultural categories without much option or choice and outside of any historical or power context.

However, diversity goes beyond hermetically sealed classifications.

Instead, it entails relations between groups in contexts of unequal power, reflecting the signification of individuals into categories that are both contested and evolving. Any reading of diversity must go beyond the cultural and discursive to embrace political economy at the level of hierarchically constructive relationships (Murray, 2005, 131).

Murray's position on the term "diversity" is important as the terms "diversity," "ethnic," "visible minority," et cetera have become increasingly contested terms in public discourse in Canada today, due to the rapid changes in demographics caused by recent trends in immigration.

Writers from diasporic communities who are considered part of the "visible minority" community, such as Michael Ondaatje, Austin Clarke, David Lam, M. M. Vasanji, Shyam Selverdurai, Rohinton Mistry, and Esi Edugyan amongst a growing list of others, have been successful in recent years in reaching literary audiences both within Canada and internationally. Their writings have explored the tensions caused by issues involving immigration, displacement, cultural assimilation, and identity and problems relating to discrimination and exclusion due to race and colour. These "diasporic voices" are increasingly at the forefront of discourses on politics, social and economic issues, and on matters of national identity and social cohesion, especially in the wake of the terrorist events of 9/11 and subsequently. They have in many cases benefited from state funded grants to pursue their writing careers. However, as writing is a solitary endeavor and does not require a large infrastructure or resources to create their work, the state apparatus involved in the writing process has been relatively minimal. It should be noted 
however that the publishing process for Canadian stories is also heavily subsidized by the Government, much the way the film and television industry is.

While these writers undoubtedly play an important role in the expression of diasporic perspectives in Canada, the primary cultural influencer in today's society is increasingly television, whether it is broadcast on conventional over the air, cable, satellites, or via the Internet and on wireless mobile digital devices. Dramatic storytelling is still the most watched and most influential in terms of societal messaging, and due to the economics of production, conventional network television is still the primary source of content in this genre. While there have been several feature films made by filmmakers from diasporic communities, most notable are writer/directors Atom Egoyan, Deepa Mehta, and Mina Shum, who have enjoyed a measure of success in Canada and internationally, the small number of films that are made in Canada annually and the difficulty in reaching audiences due to factors of competition from Hollywood blockbuster movies and difficulties in securing exhibition opportunities, the theatrical audiences for these films are relatively small. However, they are reaching a wider audience at home and internationally through Internet subscriber services such as Netflix and Hulu as well as through movie streaming Internet sites.

The success of Netflix as a distributor of programming content in Canada, while not being subject to Canadian content regulations, has caused concerns in both the production community and at the Canadian Radio and Telecommunications Commission (CRTC), the agency responsible for regulating broadcasting and telecommunications. A recent announcement by the Minister of Canadian Heritage that an agreement had been reached with Netflix to invest $\$ 500$ million in original Canadian production over five years in lieu of being subject to Canadian regulation has drawn both praise and criticism from producers of programming content, cultural 
workers, and academics. No specific measures for assisting producers from diasporic communities of colour were announced as part of the initiative. It remains to be seen what the short- and long-term impact this so-called Netflix deal will have on the Canadian screen production community.

As the most influential form of media in terms of shaping attitudes and conveying societal messages (McLuhan 1964) as well as being the most popular, television drama, in all its various genres, dramatic series, movies made for television, situation and sketch comedy shows, et cetera plays a vital role in a nation's culture (Fleras, Leonard 2002).

John Doyle, television critic for Toronto's Globe and Mail newspaper, and an advocate for Canadian-made television drama having a central place in Canadian broadcasting, wrote in 2006:

This is Canada. And this country, like any other, is simply inauthentic if its stories are not reflected back to its people. That's why Canadian publishing is subsidized, and Canadian Television is regulated. At the root of the original decades-old decision to support home-grown storytelling in print or on $\mathrm{TV}$, there was a profound consensus about the need to keep story telling alive. That consensus still exists. Sustaining the living thread of storytelling is a necessary endeavour, like ensuring health care and safe drinking water. It is another aspect of literacy (Doyle Globe and Mail 2006).

\section{Production Realities Affecting Diasporic Communities of Colour}

Not surprisingly, the realities of financing films and television programs in Canada present a significant barrier for producers and filmmakers from diasporic communities of colour. While 
the costs have fallen in some areas due to advances in technology, it is necessary, due to the fact that Canada represents a relatively small market and given the high cost of drama production, to finance productions that can compete in the marketplace, through a complex funding system which includes a combination of broadcast license fees, investment from provincial and federal funding agencies, federal and provincial tax credits and support from private broadcast funding agencies and distributors. As a result individuals who are in a position to "green light" these projects are reluctant to take risks commissioning programming from people who do not have a substantial amount of experience in productions of this nature.

Given the systemic barriers that exist, film and television producers from diasporic communities of colour, many of whom are from immigrant communities that are relatively new to Canada, with a few notable exceptions, have generally not had the opportunity to develop the networking and production/financial management skills and experience that are specific to this area and therefore are at a disadvantage.

The film and television industry, like many creative industries, relies heavily on personal relationships and professional affiliations that have developed over the years for information sharing on new opportunities, reference checking, et cetera and have created social networks that are industry specific. Becoming a member of these networks is often difficult for members of diasporic communities of colour who lack the personal and professional affiliations required to join these networks. Therefore, these networks often become exclusionary. These "networks of exclusion" though not created intentionally to exclude specific communities, simply because of the way they have developed and function, often have the effect of doing precisely that.

Television production requires large, well organized structures and resources to reach audiences, and the production values of programs produced by members of racialized 
communities, dealing with themes reflecting stories of their own experiences, and that of their communities, need to be competitive with programming from the US and Britain in order to reach mainstream audiences sought after by television networks. Budgets for drama productions range from $\$ 1$ million plus per episode for a half-hour prime-time series to a $\$ 2$ million and up for an hour. As it is virtually impossible to recoup the cost of production from the domestic Canadian market, and sales to foreign markets are difficult, producers are reliant on support from Canadian government funding sources, such as Telefilm Canada and the Canada Media Fund, which are increasingly oversubscribed.

In a fiercely competitive market, producers from diasporic communities who have had limited opportunities to develop the production, financing, and marketing skills are severely disadvantaged when it comes to competing with producers from mainstream communities who have developed their skills by working their way through the production system and have developed effective social and business networks. There have been some special funding programs instituted by agencies such as Telefilm and the Canada Media Fund to assist minority film and television producers, from time to time; however, these programs have proven to be inconsistent with little follow up and the outcomes of these programs appear to be poorly documented and analysed and have not resulted in any significant opportunities on an ongoing basis. This has resulted in many creative personnel from diasporic communities either leaving the country to seek opportunities elsewhere after an initial production, or leaving the industry altogether. (Ryerson Roundtable on Cultural Diversity and Action Plan 2012).

\section{Role of the CRTC}

As Canada's broadcasting regulator, the Canadian Radio and Television Commission (CRTC) is charged with ensuring the implementation of the objectives included in the Broadcasting Act. 
The requirement for the CRTC to ensure that Canadian media reflect the country's ethno-cultural diversity is based in Canada's Broadcasting Act (which was last revised in 1991) subparagraph 3(d) (iii), which states:

The Canadian broadcasting system should $[\ldots]$ through its programming and the employment opportunities arising out of its operations, serve the needs and interests, and reflect the circumstances and aspirations, of Canadian men women and children, including equal rights, the linguistic duality and multicultural nature of Canadian society and the special place of aboriginal peoples within that society.

The use of the word "should" in this clause has allowed for a large degree of interpretation and does not, it is argued, require specific commitments by the broadcasting system to ensuring cultural diversity are present in the system.

Over the years the CRTC has implemented a variety of policy initiatives with respect to the reflection of cultural diversity. A ruling by the CRTC requiring Broadcasters to measure current performance and set targets and goals for cultural diversity representation was an attempt to "encourage" broadcasters to improve their performance in this area. However, it is my contention that without specific requirements and the resources required for adequately monitoring and ensuring compliance, particularly in the production of English-language drama that reflects Canada's cultural diversity; gains in this area have been minimal. Even productions that were ostensibly "multicultural" and purportedly aimed at reflecting the "cultural diversity" of Canada and the "authentic voice" of people from diasporic communities of colour have not fulfilled their promises. (See case study of Little Mosque on the Prairie Chapter Two) 
Kaan Yigit, President of Solutions Research Communications Group, told the CRTC at a licence application hearing for CanadaOneTV, an application for a digital channel focusing on broadcasting English-language drama with a specific mandate to include "visible minority" people in key creative positions, ownership, and executive management, “...to catch up to today's population bench marks for the whole of English Canada, for primary characters (on TV programs), would take about 10 to 15 years. If you wanted to catch up to Toronto and Vancouver, it would take some 40 years plus" (Kaan Yigit, CanadaOne licence application hearings).

The application was created to address the lack of opportunities in mainstream broadcast television, for minority producers, writers, directors, and actors. In the interests of full disclosure I was a partner in the application and was involved from its inception to the decision by the CRTC to deny the application. While the application had widespread support from across Canada by media artists of colour as well as unions and cultural organizations, it was strongly opposed by major cable and satellite distribution companies and was denied by the CRTC on the grounds that they believed that the present broadcasting system would make the changes necessary to provide on-screen and off-screen representation of minorities. Since the decision, opportunities for racialized minorities working in screen media have substantially decreased due in part to the recent decrease in advertising revenues for mainstream media outlets and major consolidation in the broadcasting industry, which has resulted in fewer productions and major layoffs in the industry. As well, recent decisions by the CRTC to lower the minimum requirements for Canadian content in prime-time programming set for private broadcasters as part of their licensing commitments has further reduced opportunities for emerging screen-media artists, many of whom are from diasporic communities of colour. 


\section{Ethnic Television Broadcasting in Canada}

There is a widespread feeling both amongst people who work in the screen media industries and amongst the general population that "ethnic television" or what had come to be known as "third" language (after English and French) provides the outlets that are needed to represent diasporic people of colour in screen media programming.

While ethnic television has provided an important platform for diasporic communities of colour in many respects, including providing some locally produced news and entertainment programming as well as drama and comedy programs in ethnic languages from "home" countries, a close examination of ethnic television broadcasting in Canada indicates that for several reasons, the opportunities for the production of original narrative programming that reflect the lives and interests of diasporic communities of colour in Canada are very limited.

In 1985, in recognition of the increasingly diverse Canadian population, the CRTC established an Ethnic Broadcasting Policy, under which commercial ethnic radio and television services are specifically licensed to serve culturally or racially distinct groups. Ethnic television stations were required to devote at least $60 \%$ of their schedule to ethnic programming, serve a broad range of ethnic communities in the stations coverage area and generally devote at least $50 \%$ of their schedule to third-language programming. The new policy and regulatory framework was designed to provide clear and consistent guidelines for the development of a wide variety of new ethnic broadcasting services, including radio, television, specialty television services, and pay television.

In my experience, many people appear to have formed the impression that because of the existence of "ethnic media" the issues pertaining to the representation of diverse communities 
and people of colour on our screens are well taken care of. However, the ethnic and thirdlanguage channels, while serving the needs of first-generation immigrants for news and information about their "home" countries and community events in Canada, are not required by the CRTC, to produce original narrative or scripted programming that reflect the interests and realities of life in Canada for second- and third-generation immigrants from these communities because, as they have argued successfully to the CRTC, they do not have the financial resources to do so. Rather, they rely on programming produced in their "home" countries for a large part of their broadcasting schedule, as well as syndicated American programming in prime time. This consists primarily of movies, variety programmes, telenovellas, and sports programs, which are also now increasingly available free of charge via the Internet.

There have been a few exceptions to this. In 2004, as a part of its condition of its license,(COL's) Omni television (now with stations in Toronto, Vancouver, Calgary, Edmonton, and Montreal), which was originally licensed as a multi-lingual channel to serve the needs of the Toronto multi-lingual and multicultural communities, was required by the CRTC to produce 78 half hours of scripted television. They met their commitment by producing 90 half hour episodes of Metropia, night-time soap opera with an ethnically diverse cast, about a community of young artists working and living in Toronto, to fulfill the channels' multicultural mandate. The series is no longer in production.

A special funding initiative to produce Documentary programs and some drama programs by independent producers focusing on stories and issues in multicultural communities in a "third language" (languages other than English and French) was created by Rogers Communications (owner of Omni and CITY TV channels) utilizing CRTC mandated "benefit funds." These are a portion of the sale price when a network is sold to another media organization to be used for 
Canadian programming initiatives. A scripted drama series set in the Chinese Canadian community was produced through this program with supplementary funds from the Canadian Media Fund and broadcast on OMNI television in English and Mandarin.

In 2015, OMNI television broadcast Blood and Water, a Chinese crime drama series filmed and set in Vancouver and available in Mandarin, Cantonese, and English. The eight-part, thirty-minute series was produced by Breakthrough Entertainment. However, none of the principals of the company are from the Chinese community.

Recent competition from internet based screen media platforms have substantially reduced advertising revenues for "third language" channels, making funding for original programming even more difficult to access for Canadian producers from diasporic communities of colour.

\section{Factors Affecting Representation}

As a large part of the film and television programming that is produced in Canada is produced with public funds and is therefore mandated by government policies of multiculturalism and equity, as well as the Canadian Charter of Rights and Freedom, the issue of who gets to tell the story and profit from it is a public policy issue that is a frequent topic of debate, particularly within racialized communities.

It is important to note that virtually all comedy and drama programming broadcast in Canada is produced by independent production companies who are commissioned by the $\mathrm{CBC}$ and private broadcasters to produce programming in theses genres. The majority of these companies are small- to medium-size companies who are not required to meet any federal government employment regulations vis-à-vis the hiring of "visible minorities" as defined by the federal government. However, the primary institutions that are responsible for funding screen- 
based media, Telefilm Canada and The Canada Media Fund and the publicly funded Canadian Broadcasting Corporation and the National Film Board are governed by federal government policy and regulations concerning the employment of visible minorities and their reflection in screen media.

So why are there still such consistently low levels of representation in front of and behind the camera in prime-time drama and comedy programs, which are the most frequently, watched genres and the most lucrative sector for screen-media workers?

Rita Deverall, an African-Canadian actor, writer, broadcaster, educator, and former television executive, posed this question in an editorial in Playback magazine, the primary Canadian film and television industry periodical:

If potential audiences are diverse, isn't it natural to assume that diverse TV personalities and programs will sell? Other industries get it. Why is that such a difficult concept for media companies to grasp? It all goes back to who is in control. But instead of fundamental change in terms of who has the power, media companies stir up a lot of activity around “diversity"- - without changing anything (Playback 2008).

Deverall goes on to outline several "diversity smokescreens" broadcasters use to avoid making any meaningful changes in the area of cultural diversity. These include the frequent use of the word "diversity" in its communications, appointing minorities to symbolic positions, undertaking “consultations" with minorities with no real outcomes, creating "training" programs with no jobs at the end of the training, and "cosmetic" on- screen hiring as opposed to hiring minorities in management positions. 
Grace Edward Galabuzzi points to the underlying cause of this approach by mainstream institutions towards minorities in his comprehensive study of the systemic exclusion of racialized minorities in Canada's economic system,

While Canada embraces globalization and romanticizes the idea of multiculturalism and cultural diversity, persistent expressions of xenophobia and structures of racial marginalization suggest a continuing political and cultural attachment to the idea of a White-settler society. Canada has always imagined itself as a white immigrant nation, ignoring both the Aboriginal reality and the racialized immigrant population. This unresolved tension is reflected not only in racially segregated institutions such as the labour market and the subsequent unequal outcomes, but also in the quality of citizenship to which racialized group members can aspire (Galabuzzi 2006, xi).

\section{Present Realities/Systemic barriers}

In my interviews with senior administrators at Canadian Government funding agencies Telefilm Canada and the Canada Media Fund, the primary investors in screen-based media, who are funded directly by parliamentary allocation and taxes/subsides levied on cable and satellite distribution companies, they indicated that they are acutely aware of the problem of inequitable representation of people of colour in screen media, particularly in the scripted programming genre. They cited past "initiatives" and future plans to attempt to remedy the situation, including a funding program to assist Anglophone minorities in Quebec and a fund for third-language television productions broadcast on ethnic television channels. 
However, they cite two major barriers to their efforts to make substantive changes to policy and procedures that will result in more equitable representation of diasporic people of colour in prime-time narrative programming. As a primary obstacle they cite the absence of hard data concerning representation because they are restricted in gathering this information by provisions in the Government of Canada Privacy Act, which prohibits them from collecting data on racial representation in their client groups. A senior executive at a government agency said in our interview, "we discuss this issue frequently at our senior management meetings, but without hard data we cannot present concrete evidence and make policy recommendations at the board level or to the minister."

The other major barrier they said was related to the fact that there are only very few producers, who are key to the production of independently produced narrative programs, who have the necessary creative and business skills required for the development and production of this genre of programming. As noted earlier, virtually all prime-time narrative or "scripted" programs and feature films are produced by independent producers with the support of either Telefilm Canada or the Canada Media Fund.

Interestingly, by comparison to the situation involving Aboriginal peoples, the administrators from both Telefilm and the Canada Media Fund stated that it was an association of Aboriginal screen-media activists who undertook their own study in their community and presented the findings to the agencies, which resulted in special funding programs for the Aboriginal community to increase training and production opportunities for their communities.

Undoubtedly the existence of the Aboriginal People's Network (APTN) has provided an important broadcast platform as well as funding in the form of license fees for original narrative created by Aboriginal storytellers. Established in 1992 with government support to broadcast in 
Canada's northern territories, since 1999, APTN has had a national broadcast license. It airs and produces programs made by, for, and about Indigenous peoples in Canada and the United States. Based in Winnipeg, Manitoba, it is the first network by and for Indigenous peoples.

APTN has mandatory carriage status, which means they must be available as a "basic" service on all broadcasting distribution platforms (cable and satellite) according to CRTC regulations, through section 9, 1(h) of the Broadcasting Act. This provides them with a guaranteed amount of revenue annually, which is paid by cable and satellite distribution companies from subscriber revenues; hence they are able to support several prime-time comedy and drama programs dealing with Aboriginal themes. Unquestionably, the requirement by APTN that controlling interest in the production companies that produce programs for the network be held by individuals from Aboriginal communities is a further guarantee that only programs with "authentic voices" from Aboriginal communities are heard and are reflected in their programming.

Ultimately, my research led me to the Government of Canada Department of Heritage, who is responsible for both formulating policy in broadcasting and film production and monitoring the cultural industries and funding institutions and ensuring their compliance with government policies.

My interviews with senior members of this ministry, specifically those responsible for both formulating policy and making recommendations for implementation to the minister and for monitoring the funding agencies, revealed that regular consultations were held with the heads of funding agencies Telefilm Canada (for feature film and documentary features), the Canada Media Fund (for broadcast television and digital media), and with executives with the National Film Board of Canada and the Canadian Broadcasting Corporation. These Crown corporations 
are primarily funded through direct allocation of funds through parliament and they report annually to parliament through the Minister of Heritage.

The senior members of the Broadcast Policy Branch indicated that while they were aware of the issue of low levels of "visible minority" representation in screen media, they were not empowered to require theses agencies to take any specific measures to remedy this situation.

They also cited the issue of the lack of empirical data in this area of representation, particularly in prime-time narrative programming caused in part by the provisions of the Privacy Act, which prohibited the requirement by employers for employees to provide this information other than on a voluntary basis. They also stated "there is reluctance by employees to identify themselves as visible minorities on voluntary surveys. Therefore there is virtually no data on which to base policy recommendations to the Minister of Heritage in this area."

They informed me that the Ministry was in the process of doing a complete review of broadcasting issues and policies relating to the production of screen media and that anyone concerned about these issues could have input into the review through the process of public consultations and online surveys being conducted by the ministry. However, they stated that the responsibility of monitoring and regulating the representation of "visible minority" communities on broadcast media was under the jurisdiction of the CRTC, which reported directly to parliament. They noted the CRTC responsibilities for regulating broadcasters in Canada and the requirements the CRTC imposed on broadcasters to file reports annually on levels of employment and onscreen representation.

In a subsequent interview with a senior official of the CRTC, I was informed that the CRTC did "encourage" broadcasters to have equitable representation of the diversity of Canadian society and required them to file annual "diversity reports." However, I was told that 
the CRTC "did not have a mandate to regulate the employment of creative workers in the production of television programming. Therefore, private independent production companies do not fall under the jurisdiction of the CRTC." The official indicated that he was aware that virtually all narrative programming broadcast by the $\mathrm{CBC}$ and private broadcasting networks are produced by private independent production companies.

The Minister of Canadian Heritage announced the results of the consultations and policy review of broadcasting on September 28, 2017, in a policy document called "Creative Canadathe Government of Canada's vision for Canada's cultural and creative industries in a digital world." It was touted as "Canada's first-ever strategy for the creative economy and a renewed policy approach to strengthen Canada's diverse and vibrant creative sector.” The report stated:

The Government's vision for Creative Canada cannot be achieved without a commitment to diversity and inclusion, including gender parity. To strive for greater gender parity in all of its initiatives and support to the creative industries, the Department of Canadian Heritage will integrate Gender-based Analysis Plus (GBA+) across its activities, programs and services. Telefilm Canada has committed to build a more representative and diversified feature film portfolio that reflects Canada's population by 2020. To this end, Telefilm aims to achieve gender parity in the key roles of director, writer and producer for the films it finances.

While Creative Canada stated it "offers a roadmap for the future of Canada's creative industries." it did not outline any specific acknowledgement of the issue of the underrepresentation of communities of colour in the screen-media industries or any specific 
measures to engage with this issue. This is not surprising given my research interviews with members of the Canadian Heritage Broadcast Policy branch referenced earlier, in which they indicated while they were aware of the issue of the under representation of people of colour in the screen-media industries they did not have any data, due primarily to the restrictions imposed by the Privacy Act, to make any policy recommendations to the Minister in this area.

The CRTC's responsibilities and practices with regards to the representation of "visible minorities" were one of the primary areas of examination at the Ryerson Roundtable on Cultural Diversity in the Toronto Screen Media Production Industry which was convened in December 2011 at Ryerson University in Toronto to address the persistent economic marginalization of visible minority screen-media producers in the English-language Canadian screen-media industry .It other stated goal was to address the challenges and opportunities involving visible minority screen-media producers in the Canadian media industry. The Roundtable participants included national and international media leaders, scholars, practitioners, and stakeholders. With specific regard to the CRTC annual diversity reports the CRTC required broadcasters to file annually, the Roundtable stated in its Report and Action plan:

In previous years the CRTC created a policy to document diversity on screen and required broadcasters to file annual reports that would outline their results on employment and on screen representation. CRTC found very low representation of visible minorities in broadcaster employment and on screen in particular of aboriginal peoples. Out of these efforts a task force was formed and a set of best practices was produced (including the production of annual audits of the Broadcaster Diversity reports by the Canadian Association of Broadcasters (CAB). However 
since the closing of the $\mathrm{CAB}$ a few years ago, (Note. the $\mathrm{CAB}$ member organizations voted to close the organization due to decreased revenues and the high cost of maintaining the organization) the annual industry wide diversity audits are no longer prepared. While external monitoring of diversity practices can take place via the reports that broadcasters file with the CRTC, our examination of these reports shows the absence of clearly established definitions of what activities contribute meaningfully to diversity, and lack of clarity regarding the thresholds that must be met in order to ensure that various organizations have lived up to their diversity requirements. Not surprisingly in this environment, monitoring and enforcement of diversity standards are largely ad hoc, and there is little evidence of effective contributions to solutions (Ryerson Roundtable Report Policy and Challenges, 17).

There have been efforts by individual screen-media producers and screen-media artists over the past several years to lobby the CRTC to take specific measures to ensure equitable access to resources and equitable representation in front of and behind the camera for people of colour. However, these efforts have generally been ineffective due to several factors outlined in the Ryerson Roundtable report:

The diversity advocacy community also appears to have fragmented into many smaller organizations and individuals whose efforts are collectively uncoordinated. This presents the community with one of its most significant challenges. There are several reasons for the lack of sustained and coordinated efforts on increasing diversity. To begin with, 
the distinct lack of real progress creates enormous frustration and burnout among advocates who eventually give up and move on to other things. The instability of a media career is another factor that undermines political actions. Advocacy work is costly and labour intensive, particularly when it comes to policy advocacy regarding regulators or preparing interventions to the CRTC. High costs, complex processes, and a lack of progress take advocates out of the game. Visible minority media producers need a permanent, professional umbrella organization that can provide a voice, services, and strong, ongoing evidence-based policy advocacy (Ryerson Roundtable Report).

Based on the Broadcast Act, the Multiculturalism Act, and the Employment Equity Act, and in all the policy documents of the various government institutions that have been created to formulate policy and regulate the industries that are governed by these Acts- the representation of racial and cultural diversity in all sectors of screen media of Canada is a stated objective and a major priority. However, it is clearly apparent that due to systemic barriers, established industry practices and a lack of clear objectives and commitment by the institutions as well as the absence of robust regulation, monitoring, and enforcement mechanisms, the aims and objectives of the legislation are not being met. 


\section{Chapter Two \\ The CBC-Mirror or Mask of Canada's Diversity?}

In this chapter I will examine the CBC's mandate to reflect the cultural diversity of Canada both in its onscreen programming and in its employment,through its history and current record in narrative programming in this regard and through a Case Study of its television series Little Mosque on the Prairie broadcast on the CBC network from 2007 to 2012.

My personal history with the CBC began in the mid 1970s when I contributed freelance radio documentary pieces for $\mathrm{CBC}$ 's regional Winnipeg, Manitoba station and for various $\mathrm{CBC}$ Radio Network Documentary programs. I subsequently was hired as a television reporter working in Regina, Saskatchewan and in Winnipeg. I later became the host and reporter for "Canadians" a CBC Toronto local television series which celebrated the accomplishments of Canadians from multicultural backgrounds. A subsequent series took a harder look at issues which were created as a result of immigration and Canada's multicultural policy. In the 1980s I produced and directed several documentary films for the $\mathrm{CBC}$ on a wide variety of topics and created and produced "Neighbourhoods," a CBC Toronto documentary television series exploring the life of Toronto's diverse ethnic communities through its many unique neighbourhoods. A desire to produce narrative programming for primetime television and changes in the way prime-time television programs were being financed lead me to establishing an independent film/television production company in order to produce "Inside Stories," a Gemini-award (now renamed as the Canadian Screen awards) winning drama series which featured stories by writers from diverse cultural communities in Toronto. I was later contracted by the $\mathrm{CBC}$ as an Executive Producer to oversee the production of the same series by independent producers across Canada. Following major government cutbacks to the $\mathrm{CBC}$ budget 
in the mid 90's, which resulted in the series being cancelled, I was hired as the head of independent production and programming at Vision TV, a publicly owned national television network based in Toronto where I spent 7 years overseeing Vision TV's Independent production and programming.

I was contracted once again by the $\mathrm{CBC}$ in early 2000 to oversee the development of an application to the CRTC for a new television network whose mandate was to provide new opportunities for independent producers in narrative programming, with a special emphasis on reflecting Canada's diverse cultural communities. After a considerable investment in preparing an application to the CRTC for a new license for the channel, the CBC decided not to move forward with an application due to concerns over a new round of budget cuts to the $\mathrm{CBC}$ and potential opposition to the application from other broadcasters and distributors. The application later went forward to the CRTC as CanadaOne TV with investment and support of private investors but was not successful. Through these experiences spanning three decades, I have had the opportunity to engage with senior levels of management at the $\mathrm{CBC}$ as well as observe their approaches to meeting their mandates to reflect Canada's cultural and regional diversity through their programming and employment practices.

\section{Mandates and Realities}

While the official government policy of multiculturalism appears to support notions of pluralism and equity, the reality for diasporic storytellers in narrative television programming on the $\mathrm{CBC}$, Canada's public broadcaster, tells a different story. It is generally accepted that an accurate reflection of all the diverse groups in society in our media, particularly in state supported Public broadcasting is necessary for the healthy development of a civil society. 
The issue of Cultural Diversity and the participation and inclusion and representation of culturally diverse, and in particular visible minority communities at all levels of Canadian society, has recently become a key topic on the social/political agenda (Mahtani 2001, 99).

Canada has led the way in institutionalizing notions of multiculturalism and cultural diversity, through its Charter of Rights and Freedoms (1982) and The Canadian Multiculturalism Act, passed by Parliament in 1988 (Fleras 2010).

The $\mathrm{CBC}$ is one of the primary publicly supported institutions mandated through the Canada Broadcast Act, to reflect cultural diversity in all aspects of its programming. In this chapter, I will examine the experiences that diasporic storytellers of colour have in telling their stories on the $\mathrm{CBC}$ in narrative television programs .For over 65 years, the $\mathrm{CBC}$ has attempted to reflect the lives and preoccupations of Canadians to each other-in English, French, and now in eight Aboriginal Languages. It has as its major priorities, building bridges between communities, fostering understanding between cultures, and promoting Canadian values of respect, tolerance, and moderate viewpoints. Yet, from its inception, the $\mathrm{CBC}$ has struggled with conflicting imperatives, created by the realities of television broadcasting in Canada. According to Mathew Fraser:

The CBC's status as a single monopoly broadcaster obliged it to schedule programs that would appeal to the greatest possible number of people, much like the mass audience of private US networks. As a result, from the very start of Canadian television, the $\mathrm{CBC}$ operated not as a distinctive, non-commercial broadcaster, but as a mass audience outlet for the same major commercial brands that bankrolled American 
television — cigarettes, soap powder, razor blades, automobiles and the like. Thus the $\mathrm{CBC}$ was confronted with a profound paradox from the moment it went on the air: its commercialism contradicted the public service values that inspired public service broadcasters in other countries (Fraser 1999, 137).

This has continued, despite policy changes that have attempted to make CBC a broadcaster of primarily original Canadian programming in its prime-time schedule. As recently as in the past few years, the $\mathrm{CBC}$ has been strongly focused on reaching large mainstream audiences through its narrative/drama/comedy programming and competing with private networks during primetime viewing hours, through its drama and reality programming. Diasporic communities in Canada, who more recently have come from countries considered non-traditional sources of immigration, such as Asia, Africa, and Latin America, are generally categorized as visible minorities and are considered niche audiences, despite the fact they now constitute the majority in the country's largest urban areas.

However, over the years, the $\mathrm{CBC}$ has attempted, through a number of programming initiatives, to achieve its mandated goals to reflect the regional and multi-cultural reality of the country, through a variety of drama and comedy programs that were also popular with a broad section of the Canadian public.

\section{History-From King of Kensington to Kim's Convenience.}

In the early 1960 s, the popular comedy program King of Kensington was one of the first attempts to reflect the changing face of Canadian cities in prime-time television programming. Other programs in the '70s and '80s, such as Street Legal (a show about lawyers in Toronto), through its story lines and some cast members from minority communities, attempted to do the same. 
Degrassi Junior High, which first aired on the CBC, (it was later cancelled by the CBC after several seasons and subsequently broadcast by CTV as Degrassi: the next Generation) was also successful in entertaining Canadian television audiences and reflecting the growing multicultural make up of Toronto.

In the early ' 90 s, the independently produced, 26 episode, drama anthology series Inside Stories was aired in prime time initially in the Toronto region and subsequently on the national network. In the interests of disclosure, I served as the Executive Producer of the series which was produced by an independent production company I was a partner in for the first season of 13 episodes, which were set in Toronto's multicultural communities, and as an executive producer for the $\mathrm{CBC}$ for the second season of 13 programs, which was produced by independent producers across Canada. The aim of Inside Stories, in addition to telling compelling and entertaining stories that reflected both the multicultural diversity of Canada as well as its regional diversity, was to provide opportunities to writers, directors, actors, and producers from the country's culturally diverse communities to develop their talents to produce dramatic programs with adequate budgets and to appeal to a national audience in prime time. It garnered sizable audiences and received several awards, including two Gemini's, including the Canada Award for Best Multi Cultural program in 1988. It was cancelled after two seasons when the CBC suffered sizeable cutbacks in its funding.

The series had provided opportunities for writers, directors, and actors from diasporic communities of colour who had hitherto few opportunities to tell their stories on prime-time television. It also helped in building independent production company infrastructure across Canada. However, without continued production, the gains made in these areas were unfortunately lost for the most part. 
The series Drop the Beat, set in the world of Black Hip-Hop music in Toronto, was aired on the $\mathrm{CBC}$, but was cancelled after two seasons. The program was seen as an attempt by the $\mathrm{CBC}$ to represent the growing presence of the Black community due to immigration from the Caribbean in the " 70 s and ' 80 s. While it did provide opportunities for some creative screen media workers from the Black community, it was criticized for having very little creative input from members of the Black community. There were only two black writers on the script writing team and one of the 26 episode's director was black. The executive producers of the program and owners of the independent production company that produced the program were two white women who controlled the story lines and creative content of the series.

Zed, a late evening, youth oriented magazine show, also featured independently produced short films by filmmakers from culturally diverse communities, but was cancelled due to financial cutbacks at the $\mathrm{CBC}$ in the late ' 90 s.

While these programs were produced primarily by the independent production sector, the recent budget cuts to the $\mathrm{CBC}$ have also increased disparities in employment at the $\mathrm{CBC}$. According to Paul Nesbitt Larking:

Data from the CBC's Employment Equity division show that, between 1988 and 1995, there were substantial improvements in the representation of women, visible minorities and Aboriginal Peoples at the CBC. In the case of women, by 1995, employment exceeded national averages. For visible minorities and Aboriginal Peoples, there had been at least some improvement. However, in the years of devastating, major cuts to CBC staff, from 1995 to 1997 , representation of each minority deteriorated ... the massive cuts to the $\mathrm{CBC}$ have added thousands of 
qualified, media personnel to the ranks of those looking for work. The data from the $\mathrm{CBC}$ tell us that those who have managed to keep their jobs are disproportionately male and white (Nesbit Larking 2007, 169).

A widely publicized initiative announced in May 2004, to develop a daytime serial that would reflect the diversity of Canada, resulted in two pilot miniseries being produced in Halifax and Vancouver and aired in off-prime hours. The national series was not produced due to funding cutbacks to the CBC, announced by the government in 2005 .

The recently aired comedy series Little Mosque on the Prairie created some opportunities for culturally diverse writers and actors. It presented stories from a small town Muslim community on prime-time television. An examination of Little Mosque on the Prairie provides a valuable opportunity for gaining insights into the motivations and processes by the $\mathrm{CBC}$ to provide Canadians with stories from diasporic communities of colour and to fulfill mandates to reflect the regional and multicultural diversity of Canada. It is also indicative of situations faced by members of diasporic communities of colour, in telling stories from their communities on the CBC.

\section{Case Study: Little Mosque on the Prairie}

I first met Zarqa Nawaz, the creator of the concept for what was to become the hit CBC TV series Little Mosque on the Prairie, at the Banff Television Festival in 2004. She was attending the festival in the hope of finding an executive producer and a production company to help her produce a sitcom based on her experiences as a Muslim woman who held traditional beliefs living in a small Canadian prairie town. Nawaz had previously directed a few short documentary films on the subject of being a Muslim woman with traditional beliefs in Regina, Saskatchewan. 
I had, while working as the director of independent production at Vision TV conceived and developed, and later served as the executive producer for the network, for a 13 episode sitcom called Lord Have Mercy, which was set in an Caribbean storefront evangelical church and had a cast of ethnically diverse characters. It was broadcast on Vision TV. I had a few conversations with Nawaz about her concept and the long and challenging process of developing a sitcom for prime-time television.

As I was fully engaged with developing an application for a new television service in partnership with the $\mathrm{CBC}$, I was not in a position to become involved in the production with Nawaz. However, I made some suggestions on how best to proceed with taking it forward.

I received a telephone call from her later and she informed me that she had been successful in partnering with West Wind Pictures a production company then based in Regina, Saskatchewan and that they had been able to raise funds to develop the program further from the $\mathrm{CBC}$ through a special program to develop narrative programming from regional locations in Canada. Sit-com development is often a long and difficult process that can often take a year or more to find the right creative team of writers and producers before "pitching" it to a broadcaster for production, and obtaining development financing is crucial, particularly for small production companies.

I was surprised to learn subsequently that the series had been "fast tracked" in development and production and was to air on the CBC network premiering on January 9, 2007.

Following a very high-profile promotion campaign, the series premiere drew an audience of 2.1 million, an exceptionally strong rating for domestic programming in the Canadian television market, and on par with Canadian ratings for a popular American series. It was, in fact, 
the largest audience the $\mathrm{CBC}$ had achieved in a decade for an entertainment program. The series was produced for six seasons; however, with sharply declining audiences for each season.

Naturally, I was keenly interested in the developments related to the production of the series, given my interest in narrative programming that reflected the cultural diversity of Canada, and as the $\mathrm{CBC}$ had invested unprecedented amounts of money in its production and promotion. It was considered to be an enormous success for the $\mathrm{CBC}$, as it dealt with the challenging subject of Muslims living in Canada in a post 9/11 world.

My interest was also due to the fact that the series was being presented as being representative of the "authentic voice" of its creator, a Muslim woman who held traditional religious beliefs. The idea of producing situation comedy broadcast in prime-time television dealing with issues about Muslims living in a small Prairie community was a unique and intriguing idea that could have several important implications in terms of the representation of a community, that had come under extremely close scrutiny in the media internationally and particularly in North America, and about which many stereotypes existed. It was also a community that was subject to ongoing scrutiny in the media due to the terrorist attack on the World Trade Centre in New York on September 9, 2011 by a Muslim fundamentalist group.

I therefore followed the progress of the series keenly with a particular interest on how both the Muslim community and the non-Muslim white population of the fictional town of Indian Head, Saskatchewan was being portrayed. I was also interested in the critical response to the series and its reception by the Muslim community as well as the mainstream Canadian television audience.

There was naturally a considerable amount of interest by the media and television reviewers in the series, as well as academic researchers, because of the unique nature of the 
series given the social, cultural, and political aspects of the issues involved, as well as the fact that the $\mathrm{CBC}$ had engaged a public relations firm to publicize the series in the United States prior to its debut in Canada.

Prior to and following its premiere on the $\mathrm{CBC}$ there were numerous articles, reviews, commentaries, and editorials about the series in Canada and internationally. In his book Little Mosque on the Prairie and the Paradoxes of Cultural Translation, Kyle Conway undertook a comprehensive examination of the series and responses to it through textual analysis of the programs, as well as by examining the broader issues related to the role sitcoms play in sensitizing audiences to differences and similarities between people from diverse cultural groups. Conway states his examination of Little Mosque on the Prairie was:

Through the lens of cultural translation, or the acts of negotiation and mediation performed by people — the show's makers — occupying a space between different cultural communities-Muslims and non-Muslims. I say "Muslims" and "non-Muslims" rather than "Islam" and "the West" because the second set of terms hides more than it reveals. Both "Islam" and "the West" name exceptionally diverse entities that overlap and interpenetrate. (For instance, Zarqa Nawaz, Little Mosque's originator, describes herself as both Western and Muslim, not to mention feminist.) For this reason, I focus on the play between text and context, between micro- and macro-levels of analysis, in ways that echo producers' and viewers' own approaches to Little Mosque. They were reflexive in their production and consumption of the program, and their negotiations over 
its meaning were at the heart of the process of cultural translation (2017, 15).

Conway also comments on the choice of story content:

I also describe how the sitcom's conservatism, a by-product of the commercial logic that shapes Canada's television industry, restricted the range of choices the producers of Little Mosque could make. In many instances they had to erase visible signs of difference in the name of diversity, a paradox I call "saleable diversity" $(2017,5)$.

Conway's use of the term "saleable diversity" raises questions for me about who was the primary market for this "saleable diversity" and where and how decisions were made regarding what was "saleable" and what was not.

My past experience as a producer working at the $\mathrm{CBC}$ in network narrative programming gave me an insight into the process of decision making and how story content was developed, shaped, mediated, and finally approved for airing on the network. I was interested in the case of Little Mosque on the Prairie in who initiated and influenced the process of "cultural translation" Conway refers to, and how it was ultimately manifested in the programs. Conway provides a definition of his use of the term "cultural translation" as follows:

"Cultural translation" describes a set of practices shaped by a series of ideas - in short, a theory - about how people act as intermediaries between different cultural groups. In the specific case of North American television these practices result in depictions of saleable diversity. Both terms - "cultural translation" and "saleable diversity" — operate on a 
practical plane and a conceptual plane. In a practical sense, saleable diversity is what acts of cultural translation produce (Conway 2017, 13).

In addition to his review of both audience's and critics' responses to the series, Conway provides his academic methodology to his examination of the series:

My particular approaches include critical production studies and agent-oriented translation studies. Both ask how structural factors (economy, politics, and so on) exert pressure on program-makers and how program-makers in turn maneuver within their circumscribed horizons. The first—critical production studies — is concerned with the way "many film/television workers ... critically analyze and theorize their tasks in provocative and complex ways" (Caldwell 2008, 2). It is grounded in political economy and ethnography, which provide the analytical tools to reveal what I am calling saleable diversity. (Conway 2017, 11).

Conway also provides a detailed review of critical reviews of the series from both mainstream non-Muslim and Muslim perspectives through newspaper and magazine articles and blog posts during the series. He also examines Muslim representation in US Sitcoms in Post-9/11 America, such as US television productions Aliens in America, Parks and Recreation and Community, as well as the broader issue of the place of and perceptions by non-Muslim Canadians' to Muslim's in North America post 9/11.

Conway's research is a valuable addition to our understanding of the evolution of the series through an examination of the stories through the 6 seasons of Little Mosque on the Prairie aired on the $\mathrm{CBC}$ network. His conceptual use of the lens of "cultural translation" and 
"saleable diversity" is useful in examining the ultimate impact of the series on the consciousness of those who watched the programs.

However, it also raises important questions, about who controls the process of determining who actually does the translating, what conditions were imposed to make this process "saleable," and did the process of production guarantee the "authenticity of voice" of the "translator" was preserved. Ultimately, did the series fulfill its promise of providing meaningful and authentic cultural translation through the presentation of Nawaz by the $\mathrm{CBC}$ as the "authentic voice" of the series as a Muslim living in post 9/11 Canada?

During the airing of the series I participated in several discussions with members of the screen media production community of colour about the series, including the changing focus we observed in the stories, particularly in seasons two to six. The focus seemed to be increasingly shifting to comedic situations involving the non-Muslim characters and increasingly less on specific issues that might occur in a more realistic portrayal of the interaction of the Muslim community and the white non-Muslim community in the small prairie town the series was set in. Despite the fact that it was a sitcom with the necessity to entertain audiences through the portrayal of humorous situations, there also had been the underlying promise of authentic portrayals of issues and characters through the involvement of Zarqa Nawaz, the creator of the series.

My primary focus therefore in conducting the case study on the production of Little Mosque on the Prairie as part of my examination of the $\mathrm{CBC}$ 's reflection of cultural diversity, particularly of diasporic people of colour, was how the "authentic voice" of the creator Zarqa Nawaz was represented in the series and what were the circumstances that initially gave her the opportunity to present that "authentic voice" in a prime-time sitcom, and then later how and why 
the "authentic voice' appeared to be increasingly marginalized in the production and ultimately was not reflected in the production of the series.

I did extensive interviews with $\mathrm{CBC}$ executives who initially commissioned the series and others who were responsible for the creative content. I also interviewed executives from the independent production company Westwind Pictures, writers/show runners, and program consultants, about the genesis of the program and the process during the production. The creator of the program, Zarqua Nawaz, declined my request to be interviewed following the cancellation of the series. She stated in an email to me, "I want to put the experience behind me."

While I was disappointed I would not have the opportunity to talk directly with Nawaz, I was not surprised at her response. I had heard that she had told a group who had been invited to a workshop at the CBC in Toronto for "visible minority" television media creators that she had been gradually marginalized from the writing process of the series after the second season, and finally been informed she could not attend the writing room sessions. This information had already been known to individuals connected with the series and to media creators of colour who had a keen interest in it. She had subsequently declined to talk about this in interviews. I concluded that she had been convinced that it was not prudent to do so and could affect future opportunities for her.

Little Mosque on the Prairie first aired on CBC on March 7, 2007. The idea of the show was first pitched to the principals of Westwind Pictures, an independent production company based in Regina, Saskatchewan at the Banff television festival in 2004. The company obtained the rights to develop the series from Ms. Nawaz, who was contracted to be a consultant and the primary creative "voice" for the series. The reflection of the regional diversity of Canada as well as its multicultural diversity are key mandates for the $\mathrm{CBC}$. 
Little Mosque on the Prairie was developed at a time when the $\mathrm{CBC}$ was looking for ways to show its programming could compete for audiences with private television networks in Canada, and its programming was reflective of the culturally diverse population of the country. The concept — the humorous treatment of a Muslim family's experiences living in a small town in the Canadian Prairies - according to the then-Vice President of Programming, Richard Stursberg,

came at a perfect time for the $\mathrm{CBC}$, as it dealt with the sensitive issues of Muslims in Canada, in a post 9/11 world, in a humorous way. Knowing that the Canadian media rarely believe Canadian television shows are any good, we decided to use a novel approach for the publicity of Little Mosque. We planted the story in the United States, where the level of hysteria about Muslims was even higher than it was in Canada. The New York Times carried an account of the show as the lead story in its entertainment section, $\mathrm{CNN}$ sent a crew to Canada to cover it. Once the Americans had validated the importance of Little Mosque, the Canadian press could not get enough of it.... As the time came to launch the show, we poured money into it. We spent more than we ever had before. Then we doubled the budget There were camels in Dundas Square in Toronto; falafels were handed out at the train station. We bought endless newspaper, television and radio ads, Little Mosque on the Prairie was everywhere" (Stursberg 2012, 61).

It was already in development when Stursberg was appointed Vice President of Programming at $\mathrm{CBC}$ English. As part of his new strategy for the network, he was determined to prove that $\mathrm{CBC}$, 
with the right amount of promotion and budgets, "could attract large mainstream audiences." $\mathrm{He}$ had set one million viewers as the target for prime-time scripted programs, and cancelled several long running series that were not attracting audiences at that level.

The series, which was filmed in Toronto, Ontario and Indian Head, Saskatchewan, premiered with a massive publicity campaign in the months prior to its airing by the $\mathrm{CBC}$ on March 7, 2007, and drew an audience of 2.1 million, an exceptionally strong rating for domestic programming in the Canadian television market. At the end of the show's first season, the show attracted 1.1 million viewers, or an average of 1.2 million for the season. The high ratings were also due in part to the fact that Little Mosque on the Prairie was preceded by Hockey Night in Canada, which was the highest rated program on the CBC. It is a frequently used strategy for a network to use its most popular program as a strong "lead in" for a show it wants to ensure a high audience for its debut. CBC Television renewed the show for a second season, consisting of 20 episodes, which began airing on October 3, 2007 and continued to attract an average of one million viewers per episode.

Both Nawaz, the creator of the show's concept, and the production company that obtained the rights to the concept, Westwind Pictures, had no previous experience in producing narrative or "scripted" programs of any kind. It was a steep learning curve, producing a primetime scripted series — but they indicated that they were very amenable to network help and suggestions. Rebecca Schechter, a seasoned writer and show runner with extensive prime-time writing and show running credits, was hired by the production company with approval from the CBC. A "show runner" is a commonly used industry term for the person responsible for the creative aspects of the series. This includes supervising the writing team and hiring the cast and directors. They are hired by the independent production company with the approval of the 
network. While the Executive Producers are ultimately responsible for all aspects of the production including the creative and business management, the show runner is often the primary contact with the network executives who ultimately have final say on all creative content of the shows. A writing team was subsequently put together, which included the creator of the show as well as consultants from the Muslim community.

However, after the success of season one, CBC executives decided to make major changes to the creative team. Reviews of the series had generally been very positive, the concept was thought to be unique and timely, but some reviewers had suggested that the shows could benefit from more sophisticated comedic writing.

The $\mathrm{CBC}$, in what was considered somewhat of a coup by some people in the production industry at the time, brought in the show runner from the popular comedy series Corner Gas on the rival CTV network, to "ramp up" the comedy. The new show runner, Paul Mather, and his writing team were, according to people who worked on season one, given carte blanche by the CBC executives; however, they did not have any cultural knowledge of the Muslim community and this ultimately resulted in considerable mediation of the storytelling by the white writers and the shows executives. The $\mathrm{CBC}$ also wanted to de-emphasize "issues" pertaining to the Muslim community in favour of "non-controversial situations" that played up the comedic situations in everyday life that arose amongst the characters.

Attempts were made to find minority writers, but were unsuccessful. Eventually, Nawaz identified Sadya Durani, a Muslim woman, who had done a few standup comedy performances, primarily for Muslim audiences in Winnipeg, and brought her in as a story consultant and writing intern. Durani has said that because of the high turnover of writers, she was constantly in the position of having to "educate" the new writers about Muslim cultural beliefs and practices. 
Often there were jokes made by some of the writers, who were all male and all white, about the pronunciation of Arabic names and on several occasions a few writers instead of using the greeting of the Muslim faith "Salam malik om" would jokingly say "awesome blossom marigold" instead. The story lines began to be increasingly centered on the non-Muslim characters, and the comedic interpersonal issues amongst them.

CBC renewed the show for a third season on March 7, 2008. Season three premiered on CBC Television on October 1, 2008. In its third season, ratings declined substantially and as of December 2008, it was attracting a quarter of its original audience. In its fourth season, ratings declined further and as of December 2009, it was drawing 420,000 viewers a week, or twenty per cent of its original audience. Despite the declining ratings, the $\mathrm{CBC}$ announced that it had renewed the series for a fifth and sixth season on February 11, 2011. There was considerable criticism in some quarters, particularly from Conservative government members, who were generally critical of the $\mathrm{CBC}$, that the series was being renewed because the then-head of programming at the CBC English was in a relationship with one of the lead actors, Zaib Shaikh.

Insiders had reported that there was a great deal of dissatisfaction with the writing team and the storylines being developed for the new season, on the part of the key cast members who it was said wielded considerable influence with senior CBC executives. Things came to a head towards the end of the fifth season, and the incumbent show runner and writers were replaced and Rebecca Schechter, who had been the show runner for the first season, was brought back for the sixth and final season. This season began airing on CBC on January 9, 2012 and the series finale to Little Mosque on the Prairie was aired on the CBC on April 2.

My research revealed that over the course of the six seasons, the show's creator, Zarqua Nawaz, appears to have become increasingly marginalized and eventually was denied access to 
the writing room. Executives from the production company expressed in interviews that they were very distraught by the decision of the new CBC Head of Comedy to exclude Nawaz from the writing room, which effectively eliminated her ongoing input into the show, other than reading the finished scripts. This was done apparently because Nawaz had been objecting to the storylines and content of the shows, which increasingly appeared to focus on the non-Muslim characters. Nawaz confirmed this in a gathering of visibility minority producers at a workshop organized by the $\mathrm{CBC}$.

Although the concept was originally created by Ms. Nawaz, a Muslim woman, and the series was presented to the Canadian public as being representative of the attitudes, perspectives, and "authentic voice" of the creator, the primary creative inputs of the series, executive producers, show runners, writers, and directors, were not from the Muslim or minority community, and as a result, the programming content was mediated by perspectives other than that of the Muslim community. After the first season, as a result of decisions made by CBC executives, the creator of the series appears to have been increasingly marginalized from the creative process of the series. By the end of the series, in season six, the creator of the series had virtually no involvement in the programs and was not allowed to participate in the writing process.

The production of Little Mosque on the Prairie, raises important questions regarding the production processes and mediation of television programs, especially those that are ostensibly presented to the Canadian public, as representing the authentic "voice" and experiences and perspectives of cultural minorities from diasporic communities of colour in Canada. As well, it illuminates issues pertaining to the access by visible minorities from diasporic communities of colour to resources and opportunities in the Canadian television industry, and specifically the 
$\mathrm{CBC}$, which is, for the most part, governed by public, cultural, and employment policies and funded through government agencies and tax credits and levies on the Canadian television broadcasting distribution companies.

The experiences of Nawaz and the decision-making process involved in the production of Little Mosque on the Prairie also calls into question the claim by the CBC of " authenticity of voice" in story content, as the series was promoted by the $\mathrm{CBC}$ as being representative of the experiences and perspectives of a Muslim woman and her community. Billboards from the series featured a picture of the lead character wearing a hijab thereby identifying her as a traditional Muslim woman.

It was also used by $\mathrm{CBC}$ as a prime example of its commitment to "Canadian cultural diversity." However, the non-minority cultural backgrounds of key production personnel and the writing team had a major influence on the stories and perspectives presented, particularly in season's two to six of the series.

I draw several conclusions from what my research revealed of this situation. The marginalization of Ms. Nawaz from the process of the writing and production of the series highlights the issue that there is inadequate oversight of issues of representation on $\mathrm{CBC}$ television. While the CRTC and the Department of Canadian Heritage are ostensibly responsible for issues of representation in screen media in Canada there are no specific requirements in the Broadcast Act relating to these issues.

Interviews with senior managers in the Department of Canadian Heritage Broadcast Policy Branch revealed that the department, while it was responsible for overall policy goals relating to the various government policies relating to broadcasting and the $\mathrm{CBC}$ in particular, had no mandate to oversee specific practices relating to broadcasting or issues relating to cultural 
diversity. There also appears to be no public or cultural agency/union frameworks for scrutiny of the decision-making process at $\mathrm{CBC}$.

It also points to the systemic barriers that exist for racialized producers from diasporic communities to mainstream drama resources and access to prime-time airtime to tell their stories. 'Several producers from minority communities have 'pitched' the $\mathrm{CBC}$ on series ideas over the years without success" (Ryerson Roundtable Report 2010).

Despite six seasons, and over approximately $\$ 75 \mathrm{M}$ spent from publicly mandated funds (CBC, Canada Media Fund, federal and provincial tax credits), there was virtually no development of minority writers or producers. There are no specific requirements by the Canadian Media Fund, who provided the majority of the funding for the series, for minority participation/training/mentorship programs to be a part of television productions. Both Durani and Nawaz have been unsuccessful in finding further employment in the television industry to date.

It appears that $\mathrm{CBC}$ executives, in the pursuit of high ratings and what Conway terms "saleable diversity" made decisions that after the first season, increasingly marginalized Nawaz from the creative process of the production and eventually excluded her from involvement in the process of the creation of the scripts altogether.

This occurred, despite the fact that the series continued to be presented to the Canadian public as being representative of the "authentic voice" of Nawaz. The decisions of what was "saleable" in terms of diversity in the storylines appear to have been made by individuals who while being experienced narrative screen media professionals had little knowledge of the Muslim community. The central core of the idea of producing a sit com about Muslims living in a small North American community was that Nawaz would provide the "authentic voice" of her own 
experiences of being a Muslim woman with traditional religious beliefs who had experience of living in a Prairie community. This was how the series was marketed to the Canadian public and indeed to news media internationally. This was a particularly important and "saleable" idea in a post $9 / 11$ climate.

One might reasonably ask why Nawaz did not "go public" about her exclusion from the story development process and what was clearly her being deprived of her agency as the creator of the series and her voice as a Muslim woman presenting stories from her own cultural community to the larger Canadian public.

The reality is that the implications of doing so both in terms of possible financial and future professional opportunities would be a serious deterrent against doing so.

What are the lessons to be learned from this? While a considerable amount of public funds were invested in the production of LMOP, both on the part of the CBC and the Canadian Media Fund, a Crown Corporation who was the primary investor in the series as well the funding through the Provincial and Federal tax credit system, there appears to be no requirements for accountability or transparency on the part of those responsible for making decisions in these situations. Established industry practices allow for broadcast executives to have virtually complete control of all aspects of the production to ensure the production meets the objectives of the program as established by the broadcaster, and adhere to network guidelines and standards set by the Canadian Radio and Television Commission (CRTC) the regulatory body.

While it is normal industry practice for broadcast executives to make final decisions on creative and financial matters in productions commissioned by the network, there is a need to examine the process and practices involved in decision making in these situations particularly when there are issues of representation and authenticity of voice and portrayal involved. This is 
especially true in situations where the "authentic voice" of the creator is a key aspect of the production.

Ironically while decisions regarding keeping the story lines more "saleable "to the Canadian public by not dealing with social issues of importance to the Muslim community as

identified by Nawaz, I believe the increasingly diminished presence of the "authentic voice" of Nawaz contributed significantly to the increasingly diminishing audience for the series because of lack of authenticity at the core of the storytelling.

It is hard to know specifically how the marginalization and eventual exclusion from the story development process affected Nawaz psychologically as she has chosen not to speak publicly about it. However an individual close to the production told me that she was extremely upset by it and had asked someone she trusted who was involved in the story development process to "take care of my baby".

However other writers from South Asian and other racialized communities such as Himani Banerjee Bharati Mukherjee, Neil Bissoondath, and Rita Deverall, (referenced earlier) have given voice to their experience of suffering the loss of the agency and with it their sense of dignity. It is clear from their writing there is a significant psychological impact.

\section{Policy vs. Practice}

Developing talent in narrative television in diasporic communities of colour appears to be a stated priority at the $\mathrm{CBC}$. However, due to a variety of reasons, including the fact that there are no executives of colour in a position to "green light" productions, and the complicated nature of producing narrative television and the funding constructs, the advocacy efforts by diasporic community members to increase their representation in narrative storytelling on the $\mathrm{CBC}$ have by and large not been very successful, as they require sustained organization and resources to be 
effective. Observational evidence indicates that while the onscreen presence of individuals from racialized communities in both news and narrative storytelling, has increased in the past few years, the presence of racialized minorities at senior management levels appears to be nonexistent, especially in positions that are responsible for the creation of programming.

Empirical data is not available as organizations cite the restrictions imposed by the Privacy Act, which is the law that governs the personal information handling practices of federal government institutions. The Act applies to all of the personal information the federal government collects, uses, and discloses_-be it about individuals or federal employees. The Act prevents employers from asking or requiring employees to identify their racial backgrounds. However, as there are a small number of these positions, observational analysis can present a fairly accurate picture of the situation. Many in the racialized communities see the nonrepresentation of people of colour in these gatekeeper positions as an unacceptable situation, given the mandate of the public broadcaster, to reflect the cultural diversity of the population in all aspects of its operations, and given the presence of racialized minorities in the overall population.

The situation is further complicated by the challenges of financing film and television programs in Canada, due to the fact that there are limited resources available from public funds, and the Canadian market is not large enough to support the production of programming with production values Canadians have come to expect from US prime-time television programs. The $\mathrm{CBC}$ has instituted a number of policies to "encourage" reflection of minorities in its narrative programming, and attempts have been made to reflect cultural diversity in Canada, by including actors and performers from minority backgrounds in some of its mainstream programming; the 
visibility of some members of diasporic communities of colour in narrative programming has increased over the years.

There is no empirical study of the CBC's reflection of racialized minorities in its dramatic programming, in front of or behind the camera, available. In interviews with $\mathrm{CBC}$ executives responsible for diversity initiatives within the $\mathrm{CBC}$, I was informed that an internal study was being planned to obtain data in this area. However, veteran Canadian television writer and producer Jim Henshaw, in a recent critique of the CBC's dramatic programming in his blog, The Unbearable Whiteness of Being on Canadian TV, provides a perspective on the current state of affairs of narrative programming at the $\mathrm{CBC}$ as it pertains to minorities from diasporic communities of colour. Henshaw also provides publicity pictures of recent $\mathrm{CBC}$ dramatic programs, and a critique of the lack of minority representation included in the programs, to graphically make his point:

And when, as a producer, I put a project into development with a Canadian television network, especially a project that will require public money to be realized, I have to sign an agreement, which includes an acknowledgement that I will "reflect the diversity of contemporary Canadian society," and that I am also "aware of the need to increase opportunities for all those who may have been traditionally underrepresented in the Canadian television industry.

Despite this policy to "encourage" producers to reflect cultural diversity in their programs, Henshaw states that the reality is far different from the stated policy goals for several reasons, including the makeup of the programming decision makers: 
In my estimation, the current snowflake invasion on Canadian television can be laid at the feet of TV executives who don't know what makes a show popular beyond making it look like a show that was popular in some bygone era. $\mathrm{CBC}$ just prioritizes their choices and somehow, this season, there's only been enough money to pay for the white ones at the top of their list; because the Canada I see on CBC is not the one I experience when I walk out my front door.

This sentiment was echoed by many participants at the Roundtable on Cultural Diversity in the Toronto Screen Media Production Industry, held at Ryerson University in September of 2011. I have examined the findings and recommendations of the Roundtable in more detail in the previous chapter.

In 2015 the $\mathrm{CBC}$ commissioned and broadcast an hour-long drama series Shoot the Messenger from Hungry Eyes Films, a company owned by members of Toronto’s Black community. The series was cancelled after two seasons.

The half hour comedy series Kim's Convenience, which centers on a Korean-Canadian family who run a convenience store, is another attempt by the $\mathrm{CBC}$ to reflect the cultural diversity of Canada. The series is based on a successful stage play written by Korean-Canadian playwright Ins Choi. It is produced by Thunderbird Films in conjunction with Toronto's Soulpepper Theatre Company. Scripts were created by Choi and Kevin White, who had previously written for Corner Gas. Thunderbird Films has several executives who are highly experienced in the film and television industry. There are no people of colour from diasporic communities at executive level in management. 
What are the implications that few programs broadcast on the $\mathrm{CBC}$ are commissioned from producers of colour? A major outcome is there has been very little development in the creation of production companies that are owned by people from racialized communities. Recent CRTC decisions concerning the production of Canadian-content narrative programming and the continuing trend of consolidation in the film and television industry will have the result of further reducing opportunities for producers from racialized communities to create their own companies and build an infrastructure.

In interviews with senior programming executives and those responsible for "diversity" initiatives at the $\mathrm{CBC}$, it is was acknowledged that in the absence of specific requirements for programming from racialized producers to be broadcast by the $\mathrm{CBC}$, it would be left to the personal tastes of the commissioning executives to commission what they perceived to be programs that would be of interest to their audience. As well, because producing prime-time drama and comedy programs required both financial and creative skills that were usually learned through extensive experience in the industry, programming executives responsible for commissioning drama and comedy programs made decisions on which programs to commission based on the experience of the producers who were "pitching" their programs. This would disadvantage new producers who might come from diasporic communities of colour who generally lacked the experience in the Canadian system. Given budgets of approximately \$13-26 million per series, the risks were too great to take a chance on producers without a proven track record. The result is very few producers of colour from diasporic communities get the opportunity to produce programming that reflects their interests and that of their communities.

In my interviews with a number of senior executives responsible for diversity and inclusion, as well as those responsible for programming at the $\mathrm{CBC}$ several of them indicated 
they were very aware of the issue of low levels of representation of people of colour from diasporic communities in the production of drama and comedy programs. They acknowledged that despite many years of "diversity initiatives," the numbers of producers from these communities and programs being produced that represented their interests were unacceptably low. They also acknowledged that without specific requirements in this area the situation was not likely to change in the near future given the complexities of the funding and production process and institutionalized industry practices. They suggested that digital platforms such as web series and social media outlets could provide more opportunities in the future that held promise for greater representation of diasporic voices to be represented in Canadian screen media.

However, producers and creative screen media artists I interviewed from diasporic communities of colour said that while these platforms were in some instances more accessible to them than the traditional modes of production, the availability of funding to produce narrative programming for these platforms was still extremely limited and that opportunities in this area were very difficult to access, often because the same institutional barriers existed. As well, these platforms were primarily of appeal to very niche audiences and did not provide access to resources that would allow programs with high production values to be produced, and hence would not be of appeal to mainstream audiences. Netflix is possibly changing the landscape in this regard. It is a phenomenon that needs further investigation.

\section{Conclusion}

According to observational analysis and information provided by a representative of the Canadian Media Guild, there are currently no members of visible minority groups at senior management positions at the $\mathrm{CBC}$ who are responsible for the commissioning of narrative television programs. This has important implications, with respect to the perspectives being 
represented in the decision making process, as well as aspects of equity, as outlined in legislation relating to the employment of members of visible minority groups. It raises questions of whose "image" of Canada is being represented on CBC Television's narrative programming, and who has input into the decisions that create this image. While there have undoubtedly been some improvements in the level of representation of racialized minorities in CBC Television News programming in the past decade, unfortunately, in the area of narrative television i.e. dramatic and comedy series - the most watched and influential in terms of societal messaging — there has been extremely little consistent progress.

As there is little empirical evidence available pertaining specifically to this area, for reasons outlined earlier, observational evidence indicates that levels of representation of racialized minorities from diasporic communities in front of and behind the camera, in narrative storytelling on the $\mathrm{CBC}$, compared to overall population, is still extremely low and certainly nowhere near population levels, especially in urban areas where the majority of programs are produced.

Without a firm commitment by the government, articulated through the Broadcast Act, and administered and enforced by the CRTC to having clearly defined goals and specific commitments by the public broadcaster in reflecting cultural diversity in front of, and behind the camera, diasporic communities of colour will continue to be marginalized and represented only in a tokenistic way, and the changes needed to allow full participation will be extremely slow in coming.

There appears to be an absence of specific, regulatory requirements, to increase representation in front of and behind the camera, in the present CBC Television framework, and an absence of adequate mechanisms to monitor progress in this area. The CRTC's jurisdiction is 
currently limited to who and what is represented on screen, and not to issues of employment and decision-making. This is especially true of independent production companies who are not subject to many of the requirements imposed on federal government institutions in this area. As well, there are no advocacy organizations with the resources necessary to engage the regulatory/political process in this regard.

This is cause for concern, given the important role television plays in many key areas of our public sphere, and its effect on identity formation and sense of belonging, especially for members of minority and racialized communities, who are a rapidly growing sector of Canadian society. Therefore, a comprehensive review of the CBC's initiatives and current status in this area, with opportunities for stakeholder and public input, and an examination into amendments to the Broadcasting Act, to ensure necessary changes are made, is required.

One of the risks, apart from the moral and employment equity implications, of the $\mathrm{CBC}$ and the CRTC not having specific requirements to fulfill the mandate of the Public Broadcaster, as set out in the Broadcasting Act, which was last revised in 1991, with regards to the accurate reflection of the diversity of Canadian society in all aspects of its operations, is that the resulting marginalization and exclusion, will result in loss of a sense of belonging, and ultimately disassociation from mainstream Canadian culture (Reitz, Banerjee, 2006).

This has important implications for the future of Canada as a nation, given the current trends in population growth and immigration. As well, Canadian society will not have the benefit of the rich diversity of voices and perspectives that exist in the racialized communities, on its public broadcaster, in a form that is increasingly influential. If given equitable opportunities to express 
themselves in narrative television, far and away the most watched genre of television, members of diasporic communities of colour would make valuable contributions to the process of crosscultural communication and understanding, and contribute to the process of nation building and the forming of national identity. 


\section{Chapter Three \\ An Analysis of Deepa Mehta's Heaven on Earth}

Deepa Mehta's film Heaven on Earth provides valuable insights into the experience of diasporic filmmakers of colour working in the feature-film sector of screen-media industries in Canada. As Mehta is a Canadian with origins in India, who had achieved success both in Canada and internationally, I wanted to investigate her journey as a diasporic filmmaker of colour in Canada and how cultural policies, institutional practices, and economic realities affected her work and allowed for the expression of her "authentic voice". The particular circumstances of the production of Heaven on Earth both on the creative level and the issues relating to the financing of the film, as well as Mehta's willingness to provide me with access to her process and experiences in the making of the film through extensive interviews with her, created a valuable opportunity for analysis.

Mehta was born in Amritsar, Punjab, India and after graduating from the University of Delhi with a Masters degree in Philosophy, began her career as a documentary filmmaker focusing on social and development issues. She immigrated to Canada in 1973 after marrying her Canadian-born husband Paul Saltzman, also an acclaimed documentary filmmaker and film and television producer. She continued her documentary career in Canada, working with her husband on several projects. She also worked independently as a director, branching out into television drama in the CBC series Inside Stories (1988) and Danger Bay (1990-1991) and later on the George Lucas television series Young Indiana Jones.

After making her first dramatic feature film, Sam and Me (1991), a comedy/drama, which explores the relationship between an elderly Jewish man and a young Indian immigrant man who 
was employed as his helper, (it won Honorable Mention in the Camera d'Or category of the 1991 Cannes Film Festival) she directed Camilla (1994), starring Bridget Fonda and Jessica Tandy. The film was not well received critically. In 2002, after the aborted attempt in India to make the film Water she wrote and directed Bollywood/Hollywood, a light-hearted romantic comedy set in the Indian community in Toronto for which she won the Genie Award for Best Original Screenplay. Mehta also directed The Republic of Love, set in Canada (2003). Heaven on Earth premiered at the 2008 Toronto International Film Festival.

Mehta is best known for her "Elements Trilogy," Fire (1996), Earth (1998), (released in India as, 1947: Earth,) and Water (2005), which she completed shooting in Sri Lanka. Water was both a financial and critical success. The trilogy starred several high profile actors from Indian cinema, many of them major Bollywood stars, including Aamir Khan, Shabana Azmi, John Abraham, Rahul Khanna, Lisa Ray, and Nandita Das. All three films were shot in India and have soundtracks composed by A. R. Rahman, who won an Academy Award for his score of the film Slumdog Millionaire.

Heaven on Earth was the first film she made following the international success of Water, which was a finalist in the Oscars for Best Foreign Language Film category representing Canada at the Academy Awards in 2007. As a result she was much sought after as a writer/director by both Hollywood studios and Canadian producers. It appeared that both the critical and commercial success of the film assured her reputation as a successful international filmmaker and allowed her to write and direct Heaven on Earth with a considerable amount of freedom to express her "authentic voice" as a diasporic woman of colour in the storytelling of the film. If my research proved this to be true, Mehta's experience of making this film could serve as 
a model for the unmediated expression of "authentic voice" by diasporic filmmakers in feature films and other screen media in Canada.

Deepa Mehta and I first met over 30 years ago, when she was living on Wards Island, a short ferry ride away from Downtown Toronto. People who lived there at that time were considered part of the "counter-culture"-hippies and artists. It is surprising that we hadn't met before, as we were both filmmakers and immigrants from India.

There were very few people who fit that description in Toronto at the time. Mehta and her husband, Paul Saltzman, had recently completed filming a widely acclaimed international documentary film series called Spread your Wings, about young men and women (mostly men) who were apprenticing with their parents, learning the family trade. Paul was the cinematographer, and Deepa the sound recordist. She later directed a number of documentary films in Toronto. I worked as a radio and television reporter at the $\mathrm{CBC}$ and had directed a documentary film about a young painter, a political refugee from the Soviet Union, who had recently completed a large mural for St. Michael's Cathedral in Toronto. I had also been the host and reporter for Canadians, a documentary series for the $\mathrm{CBC}$ profiling outstanding individuals from Toronto's multicultural communities. Somehow our paths had not crossed, but I looked forward to meeting Mehta at some point as I admired her work and was curious about her experiences as a fellow immigrant from India working in the film and television industry in Canada.

After completing the Canadians series I was contracted by the $\mathrm{CBC}$ to coordinate a new initiative to train eight journalists from visible minority communities to become reporters for the CBC's national news service. The program was created to provide intensive four-month training in television news followed by a six-month placement in $\mathrm{CBC}$ news departments across the 
country. The initiative, known as the CBC Visible Minority Journalism Training Project, was developed with the CBC Television Training Department and the Multiculturalism Directorate of the Canadian Government. Its goal was to "fast track" members of visible minority communities who had already developed communication skills and train them to become television journalists to create visible minority representation on the network news service, of which there was none at the time.

Mehta applied to be one of the trainees, and I interviewed her to assess her suitability for the program. Given her academic (Delhi University Masters in Philosophy) and professional credentials — she had directed, amongst other films, 99: A Portrait of Louise Tandy Murch (1974), about a feisty elderly feminist, which won a Canadian Film Award for Best Short Documentary, and an extremely passionate and well written statement about why she wanted to be in the program, she was one of 18 people chosen for an interview. Subsequently she was selected as one of the eight trainees by a panel of CBC executives.

After her training she did her placement in the local Toronto CBC news department. As the funding for the non-CBC employees involved with the program ran out after the training period and I moved on to work on other projects, I was not in close touch with her during this time. I heard subsequently that her experience in the Toronto newsroom had not led to her gaining a position as a National news reporter with the CBC. In fact, none of the other members of the program had, for a variety of reasons, remained working at the $\mathrm{CBC}$.

My next professional connection with Mehta was in the mid-eighties during the production of Neighbourhoods, a 13-episode television documentary series I produced for CBC Toronto television, exploring Toronto's multicultural neighbourhoods. Each episode was directed by a director who lived in and had close ties with their neighbourhood. Mehta directed 
the episode on The Annex, the neighbourhood she had lived in for a number of years and knew well. A short time later I became the Executive Producer for Inside Stories, a drama anthology television series whose mandate was to tell stories from Toronto's multicultural communities and provide opportunities for writers, directors, and actors from these communities. It was produced by an independent production company and broadcast on the CBC and CFMT television in Toronto and financed by Telefilm Canada and the Department of Canadian Heritage. Mehta had returned to documentary production but wanted to focus on directing narrative drama and applied to direct one of the episodes. She subsequently directed an episode entitled "The Twin," which was written by Toronto writer Romany Cuevas about Jamaican twin brothers who had been separated as young children in Jamaica, and had been raised in very different environments, but were later reunited as adults in Toronto. It was her first television drama and it established her skill as a director of dramatic narrative film. She subsequently went on to direct episodes of the CBC/Disney television series "Danger Bay" and "Young Indiana Jones."

In the late eighties she started developing her first feature film script, and in 1991 she made her feature-film directorial debut with $\operatorname{Sam} \& M e$, a story of the relationship between a young Indian boy and an elderly Jewish man in the Toronto neighbourhood of Parkdale. Acclaimed Indian actor Om Puri starred in the film. It won Honorable Mention in the Camera d'Or category of the 1991 Cannes Film Festival. I attended the premiere screening of the film and was delighted by the reception it received and the enthusiasm of the audience.

The film was produced by Paul Saltzman, who had great difficulty in raising the budget from Canadian funding sources. Mehta was critical about the lack of support by Telefilm Canada, for her work, and their lack of support for other Canadian racialized filmmakers. At the time Telefilm Canada had a policy of not supporting films that were set in countries other than 
Canada and involved stories and actors that were not considered Canadian. There was much discussion in the film production community at about what qualified as a "Canadian" film. Emerging filmmakers from diasporic racialized communities began to make films about their own experiences, which often involved setting part of, or the entire story, in the country they or their parents had immigrated from. I naturally followed these discussions with great interest, as I was aware that the outcome of these discussions could affect public policy relating to film production in Canada, and could ultimately affect my own opportunities as a filmmaker and those of my friends and colleagues who were also from non-white diasporic communities. Mehta's film Fire, the first in her "Elements" trilogy (Fire 1996, Earth 1998, Water 2005), which was financed through a transnational co-production (with financing from India , the U.K and Canada) and filmed in India with non-Canadian actors in the Hindi language, helped shift the conception of what constitutes a Canadian film. It opened the Perspective Canada programme at the Toronto International Film Festival (TIFF) and won the award for Most Popular Canadian Film at the Vancouver International Film Festival. This was a major vindication for Mehta, who had been openly critical of Telefilm Canada's reluctance to back films with ethnically and culturally diverse subject matter, especially shot in locations outside Canada. She had lobbied hard for support for films by Canadian directors from racialized communities that explore stories and themes from their own and other multicultural communities, regardless of where they are set. Water, which enjoyed international critical and commercial success, was nominated for an Academy Award representing Canada in the best Foreign Film category. This cemented Deepa Mehta's reputation as a Canadian film director, even though the setting and subject matter of the film was not located in Canada. 
Mehta's most recent film, An Anatomy of Violence, which investigates one of India's most notorious crimes, the 2012 gang rape and murder of a 23 -year-old woman on a Delhi bus, was also shot entirely on location in India. The film chronicles the events leading up to the rape, and explores the lives of the characters involved. The men already on board the bus-five passengers and the bus driver - gang-raped the woman, beat her friend, and threw them onto the street. The woman died of her injuries two weeks later. The case made worldwide news and was instrumental in galvanizing public outrage and Indian policy discussions about women's rights and the government's duty to prosecute for rape. Mehta was visiting her mother at the time and was deeply disturbed by the incident. The film was shot on location in Delhi, employing an "experimental" style, using improvisation and mostly hand held camera work on a very low budget. The Toronto Film Festival where the film first was screened called it "her angry, impassioned, and essential new film."

I recently attended a Press and community organization screening for the film and was surprised to hear her say at the screening that Telefilm Canada had not supported the making of the film in any way. She appeared to be quite upset by this. I later asked David Hamilton, the producer, why Telefilm had not supported the film and he said he was in "negotiations" with them to assist with post-production costs and was hopeful for support. Telefilm had initially indicated they would not contribute financially to the production of the film. I was struck by the fact that despite all her successes as a director since her first feature film in 1991, she appeared to be in the same position as she was at the start of her career with regards to Telefilm Canada, the primary funder of feature films in Canada.

An Anatomy of Violence is a continuation of Mehta's exploration in her own "authentic voice" as she writes and directs her films, of one of the major themes that defines her work - that 
of violence against women, gender inequality, and society's complicity in the subjugation of women's rights. She has explored this subject in several of her films, both in documentary and Drama, and most successfully in her 2008 feature film Heaven On Earth which deals with domestic violence in the Punjabi community in Brampton, Ontario, where a large number of immigrants from India live.

The film's subject was a matter of concern for many people in the Indian community who felt their "dirty laundry" was being aired to the wider community. The issue of spousal abuse in the Indian community had received widespread attention in the press due to recent cases that had come to light in Vancouver and Toronto.

Heaven On Earth was made after the success of Water, the third film in the Elements trilogy. Water was both a personal and critical triumph for Mehta as she succeeded in making it after suffering a major setback during the initial attempt at producing the film in India. Mehta was forced to shut down production when mobs destroyed her sets and forced the cancellation of the film shoot. The ostensible reason was that Hindu fundamentalists objected to the depiction of the way widows were treated in traditional Indian culture, as well as the fact that she had already earned the ire of fundamentalists because Earth, one of her previous films, depicted a same-sex love affair between two married women in India who were suffering abuse in their marriages. Water was subsequently shot in Sri Lanka with considerable effort to minimize publicity about the production in order to avoid similar incidents taking place in that country.

Interviews I conducted with Mehta and David Hamilton, the producer of both Water and Heaven on Earth, revealed that it was the success of Water that allowed Mehta the creative freedom and financial resources to write and direct Heaven on Earth without mediation from financial investors, such as Telefilm Canada and the National Film Board, the primary financial 
backers of the film. It is unusual in the film industry for a director to have the creative freedom that Mehta had in making Heaven on Earth. Most are subject to some degree of mediation in the storytelling process by executives at the agencies that fund feature films in Canada. I will elaborate on this in greater detail later in this chapter.

Heaven on Earth provides an example of how the political economy of feature film production functions in the majority of instances in the Canadian context. As well, the film reveals much about Mehta's creative process and commitment to the themes that are common to many of her films, which primarily include gender issues, the treatment of women in both traditional and modern society, and the effect of immigration and racism on individuals and families.

I will examine Heaven on Earth, and analyze it through the critical, theoretical lens of "accented" or "diasporic" cinema, as put forward by Hamid Naficy in his book, An Accented Cinema: Exilic and Diasporic Filmmaking. As well I will explore how Mehta's previous success as a filmmaker played an important role in her being able to preserve her 'authentic voice" in the film.

While the complex work and world of a filmmaker such as Mehta, with her Indian upbringing, her experiences as an immigrant in Canada, and her influences of Indian cinema, both Bollywood and art house styles, exemplified by Bengali director Satyajit Ray, a major influence on Mehta's filmmaking, as well as classical Hollywood styles of filmmaking (she grew up watching Hollywood movies in the movie theatre her father owned in Amritsar, India) are not easily theorized, Naficy's approach of situating filmmakers such as Mehta as "accented, exilic, and diasporic" provide a valuable critical lens with which to examine her work. 
Naficy states that:

This is by no means an established or cohesive cinema, since it has been in a state of perforation in terms of its output, which reaches into the thousands, its variety of forms and diversity of cultures, which are staggering, and its social impact, which extends far beyond Exilic and Diasporic communities to include the general public as well. If the dominant cinema is considered universal and without Accent, the films that Diasporic and Exilic subjects make are Accented ... the Accent emanates not so much from the accented speech of the diegetic characters, as from the displacement of the filmmakers and their artisanal modes of production ... consequently, they are simultaneously local and global, and they resonate against the prevailing cinematic production practices, at the same time they benefit from them (Naficy 2001, 4).

I will argue in this chapter, that these criteria locate Deepa Mehta's film Heaven on Earth in this genre of filmmaking — a genre that is relatively new, having developed post-World War Two, and was created by the recent major diasporic movements from east to west. It is also an increasingly influential form of cinema, reaching audiences in both the home and host countries .Naficy also argues that this mode of filmmaking is most often employed by filmmakers from diasporic communities as it is less costly than traditional forms of filmmaking and therefore more accessible to filmmakers who are not established and new to the communities they are living in the West. 
I will examine the themes the film explores, relating to home, place, immigrant experiences, family relationships, and ideas of identity and belonging and how they are affected by the process of immigration, themes common to many diasporic films.

As well, I will examine its style and the narrative that Mehta has employed, to create what I believe is a unique and important film, which not only addresses a controversial social issue in Canadian society, but also allows us to experience Mehta's evolution as a filmmaker through the craft of the film, and the filmic language she employs.

Naficy also takes the position that:

Accented filmmakers are not just textual structures or fictions within their films; they are also empirical subjects, situated in the interstices of cultures and film practices, who exist outside and prior to their films (Naficy, 19).

I will also examine the specific situation involving the financing and production of the film and how the unique circumstances, following the success of her film Water, allowed Mehta the artistic freedom to tell the story in her own "authentic voice" which was key to the success of the film.

\section{The Film}

Heaven on Earth (2008) stirred a considerable amount of controversy in the Indian community, as it examines the sensitive issue of spousal abuse. Mehta responded to criticism of her choice of subject matter by saying that" the complex and multi-layered community is now secure enough with itself in Canada to look at problems openly and honestly "(Mehta 2016).

The inspiration for Heaven on Earth came to Mehta when she was promoting her film Water in Edmonton. She met an Indo-Canadian woman who told Mehta she had come to Canada 
though an arranged marriage, but was now divorced. When Mehta inquired as to the reason for the divorce, the woman said it was because her husband used to beat her. Mehta had previously directed a documentary film on the effects of domestic violence and spousal abuse on children of immigrant families called, Let's Talk About It (2005). With regards to the theme of Heaven on Earth, Mehta said:

It's about domestic violence, yes, but it's also about immigration ... how young girls leave their homes, their security, their parents and their families ... the smell of their own land, and leave it all behind and go to another country, and talk about that country being, "heaven on earth;" the title is ironic.

During a rehearsal for a scene at a family dinner Mehta gave directions to the actress playing Rocky's mother, saying:

This is not 'heaven on earth;' you've got yourself a new slave ... this is not melodrama, this is about being hurt, about being let down; not only have you been let down by your family, you've been let down by your country ... I want a feeling of sadness (EPK, Heaven on Earth, 2008). Given recent publicity of several instances of domestic violence occurring in the South Asian community, the issue of spousal abuse is a sensitive one, but for Mehta the film is not just about domestic abuse. She states in an interview:

The film is not just about "domestic abuse," it's about abuse. It is also about the emotional erosion of human beings. In fact, the role of Rocky (the female protagonist Chand's husband) is one of a man who is also 
abused by circumstances that bind him to act out. There is also the abuse related to the circumstances of each of the other members of the family. So, the film is not about domestic abuse, but about abuse—-how we abuse our parents and siblings and how they abuse us. Also, on the larger scale, how we're abused by society. This, for me, is a very important theme of the film. Moreover, coming to the West from the East can also be an abuse if you're not prepared for it.

While the main story line is about the terrible experiences of an abused wife, who is cut off from her own family in India, as she has come to Canada through an arranged marriage, the themes that Mehta explores are those of immigration, racism, cultural adjustment, and traditional family relationships and behavior. These are themes common to many diasporic films from countries around the world. The film specifically examines the alienation and isolation many women encounter when they are part of an arranged marriage, which is still a common practice in large parts of the Indian community in Canada.

The protagonist of Heaven on Earth is Chand (played by Bollywood star Preity Zinta), a beautiful young Indian woman, who comes to Canada after a joyous pre-marriage celebration with friends and family in India, to marry a man she has never met, as part of an arranged marriage.

She arrives in mid-winter to a suburb of Toronto and becomes part of a family that live in a cramped, two-bedroom house and who are struggling to survive. In order to make ends meet, the parents of Rocky, her new husband, rent out their bedroom during the day, while they spend their time in a suburban mall-a situation faced by many recent immigrant families in Canada. 
This is certainly no immigrant dream of a happy and affluent life in the West. Rocky is an extremely frustrated young man, because of the subtle and overt racism he is subjected to, and very soon takes out his frustrations by brutally battering his wife.

She is also abused by her mother-in-law, and when she attempts to resist, is beaten mercilessly by her husband, with the tacit support of the rest of the family. The father is portrayed as a passive man, who, except for one instance, when his son viciously beats his wife in front of the whole family, turns a blind eye to her plight.

Chand attempts to deal with the abuse by retreating into a fantasy world of happiness and bliss, by reciting a beautiful poem recited to her by her mother when she was a young child, that evokes happier times with her family at home in India. Eventually, she is forced to undergo a ritual test of her fidelity as a wife, when she is falsely accused of adultery by her husband. The test involves her handling a King Cobra, a poisonous snake that is purportedly living in the garden of her husband's family home. In some cultures, the snake is symbolic of sexuality, deceit, and temptation. However, Mehta points out in her director's commentary in the DVD supplementary feature that in Indian culture the snake has a positive symbolism, representing strength and truth. The snake as a symbol begins to play an increasingly important role in the film, and according to Mehta, represents the duality Chand sees in her husband, "the good Rocky," who treats her kindly and with respect and "the bad Rocky," who beats and abuses her. As the film progresses, the lines between reality and Chand's surreal fantasies increasingly blur, to the point that we are not sure if what is being portrayed is in fact reality, or if it is part of Chand's inner nightmare/fantasy, imaginary world. The film culminates when Chand, with the assistance of her street-smart but empathetic co-worker, a black woman who is an immigrant from Jamaica, who is portrayed as a strong empowered woman, escapes the 
nightmare she has been living, and asserts her right as a human being to live free of abuse and indignity.

Mehta has also commented on the importance of the feelings of dignity, especially for new immigrants, and how immigrants are often stripped of their dignity by the situations they encounter in both their personal and professional lives. The film provides insights into the cultural practices and realities of a large section of the Indian immigrant community in Canada, specifically that of the Sikh community. Mehta, having been born and raised in the Punjab, speaks Punjabi fluently, and the film is almost entirely shot in Punjabi. Her familiarity with the culture notwithstanding, Mehta recognized that her life in Canada was privileged by comparison to the working class, new immigrant family she was portraying. Consequently, she undertook extensive research in the Sikh community, which makes the film an ethnographic document as well as one with a powerful social message. Scenes involving family life at home, in the workplace, and in the place of worship, as well as social practices adapted to Canadian culture, such as the use of flower bouquets during wedding celebrations and honeymooning in Niagara Falls, are examples of this.

The power of the imagination is an important theme in Heaven on Earth, as well as in other diasporic films. It is what allows Chand to survive the continual abuse she suffers at the hands of her husband, and to find the strength to resist. Ultimately, she leaves him and the oppressive situation she has been thrust into by an arranged marriage. Mehta skillfully expresses Chand's imagination through representations of her inner life, as expressed by her reciting of poems from her childhood and the imagining of the King Cobra, with its powerful symbolism.

The King Cobra, which is a central image in the film, is a snake that is often a part of Indian mythology. It is a snake that can take on any guise and is part of the headdress of the most 
powerful Hindu God, Lord Shiva. Mehta has explained that a central theme of the film is the increasing withdrawal of Chand into an inner world that she conjures up during and after the abuse she suffers. Her imagination is a key element in her survival, as expressed through the poems she recites and the imaginary snake, that later manifests itself as a real snake in the ordeal her husband forces her to go through to prove her fidelity.

She passes the ordeal triumphantly and while a reference is made by one of the family members that the snake is a Mississauga rattler, a highly poisonous snake that lives in a hole at the foot of a tree in the garden, in the film sequence, the snake turns into a hooded Cobra, which is a snake common only to India.

\section{Style/ Production Context}

There are several scenes that are shot in grainy black and white, which according to Mehta accentuates the feeling of the increasing isolation Chand feels in Canada, as well as the alienation and dislocation Rocky feels from mainstream Canadian society. It also adds to the feeling of his increasing frustration, as the pressures of his responsibilities as a primary wage earner for the family become increasingly hard to bear. He is obliged to sponsor other family members as immigrants from India, bringing them into the already overcrowded family home. The black and white technique is also used to portray Chand's fantasy life, adding another stylistic, textural layer to the film.

The attention to detail in the sets and locations is impressive, particularly as the film had a very modest budget. Diasporic filmmakers generally work with low budgets, unless they have, through the success of their earlier films, come to the attention of Hollywood studios, and are making larger budget films aimed at mainstream American audiences. 
Following the major success of Water, Mehta told me in an interview that she received many offers from Hollywood-based studios to direct films for them. She was contracted to develop and direct a film for a major studio, set in Korea and the USA, but found that she spent most of her time working on the script for Heaven on Earth. She eventually abandoned the US project to concentrate on Heaven on Earth, which she said she knew had much less chance of commercial success, and ultimately less international exposure for her given the subject matter, but "was a story that needed to be told." As well, the financing for the film, albeit on a modest budget, was available through Canadian funding sources, due to the success of Water as the production company that produced it (co-owned by herself and her husband, David Hamilton, who was also the producer) was eligible for funding from Telefilm Canada without the usual creative approval requirements. This allowed Mehta to develop the film as she saw fit. The National Film Board of Canada, who at the time was supporting a limited number of lower budget feature films with social issue themes, was also on board as funders.

Hamilton stated to me in an interview that the reason Mehta had a large degree of creative control of the film, was that the normal creative approvals, and eligibility for funding requirements that were required by Telefilm Canada policies at the time, were not a factor given the production companies successful financial track record. As well, the financial support of the NFB, and the availability of production tax credits through the Government of Canada and Ontario government tax credit system allowed the film to be made. He said that this was a "unique situation" and one not likely to be repeated. (Primarily due to major budget cuts, the NFB no longer supports the production of dramatic feature films.)

Even so, according to Hamilton, it was challenging making the film on the available budget given that the film required some shooting in India, which while rentals of locations and 
related costs are relatively modest compared to Canada, it entailed travel and accommodation costs for the cast and crew. However, this was mitigated by the fact that once in Canada, only a few locations were required to tell the story. The locations in the film, particularly in Canada, fit into Naficy's theorizing of the spaces depicted in diasporic films. In Diasporic filmmaking, the evocation of space, both figurative and real are important tropes, and in Heaven on Earth, the spaces in Canada are, by and large, narrow and oppressive, and often evoke feelings of suffocation and claustrophobia.

This fits with Naficy's description of some of the influences on "Accented" filmmakers and "Accented" styles of filmmaking:

For many exiles, the separation from the homeland, the loss of status, language, culture, and family, and the fear of the hostile host society, may constitute sufficiently "excessive adverse life events," to lead us to expect to see in their lives and their films, agoraphobic and claustrophobic spatiality. As liminal exiles and interstitial filmmakers, Accented directors are less apt to follow the conventions of established genres, or the styles of dominant cinema, than to inscribe in their films their own torqued and tortured experiences (Naficy, 2001, 188-189).

Mehta primarily uses Bollywood actors in her films, because as she states:

There are very few actors of Indian origin in the West, apart from British Indian actors Naveen Andrews and Jimmy Mistry, who act frequently in British and Hollywood feature films. While there are a growing number of actors in Canada from South Asian backgrounds, to date there have 
been few leading roles for them through which they could gain the experience required to play main characters in films.

\section{According to Khorrana:}

Therefore, it appears that Mehta's decision to use Bollywood talent in her films is driven by circumstance as well as a possible strategy, to raise the profile of her films amongst mainstream Indian and diasporic audiences, thereby facilitating the crossover. Despite Mehta's disavowal of certain ideologies, practices and styles, characteristic of commercial Bollywood, she is both influenced by a certain era of Indian cinema and is willing to use Bollywood talent and tropes in her films (Khorrana, 2011).

Mehta has also noted, that due to the fact there are no companies that specialize in supplying South Asian actors as extras, she used people from the community, many of whom were friends of people she knew and local people from the Sikh temples in the Brampton community. Adding to Naficy's categorization of Mehta as a Diasporic filmmaker, a further elaboration on her own identity as Indian born, but Canadian by cultural influence and citizenship, is provided by Levitin, who refers to her as a "transnational, feminist, and independent filmmaker.”

The ability to manipulate content, aesthetics and perhaps controversy, defines Mehta's special talent as an independent filmmaker, competing in the global market. A more precise description of Mehta as filmmaker, might be as a transnational, attuned to the cinematic traditions of two very dissimilar societies, a feminist, with distaste for rigid nationalisms 
and power relationships, and an independent filmmaker, with an early, honed instinct, for the art film exhibition (Levitin 2003, 274).

\section{Conclusion}

After screening the film several times and listening to Mehta's commentary during the film, I was struck by the great lengths Mehta went to authentically portray the cultural practices within the Punjabi Sikh community. She did extensive research within the diasporic Sikh community in Brampton, and no doubt her early work as a documentary filmmaker proved to be a valuable asset in the making of this film.

Mehta said in a recent interview with me that her film Bollywood/Hollywood (2002) was her "love song to Canada," in which case, Heaven on Earth, is in many ways, a lament for lives of immigrants, who suffer loneliness, isolation, dislocation, a profound loss of dignity and identity, and economic deprivation. This is particularly ironic, given the expectations that their newly adopted country would be "heaven on earth." This irony is particularly true for women, who also often bear the major brunt of their husbands' and families' frustrations.

The film is a powerful testament, not only to the horrific impact domestic abuse has on vulnerable women, particularly those who come to Canada through an arranged marriage, which is still common practice in some parts of the South Asian community, but also to the various forms of abuse, both subtle and overt, many immigrants suffer because of racism and a loss of dignity. Mehta stated in her commentary on the film:

I really wanted to get into the head of an abused woman ... to feel the confusion ... to understand the state of mind of a woman who is being abused. I also wanted to show how young girls can observe abuse in their family and grow up thinking it is normal. 
In my opinion, in this she has succeeded admirably. The film is often difficult to watch, because of the pain suffered by Chand and what appears to be the unrelenting attitude of her husband and the seemingly indifferent reaction of the family, who observe closely all that is happening to her but do nothing to prevent it. It is also challenging and frustrating at times, as it uses stylistic techniques that can be confusing in terms of understanding what is real and what is imaginary. Some film reviewers and fans of Mehta's previous films that employed more conventional techniques found the stylistic methods used by Mehta in Heaven on Earth disconcerting.

Mehta's comments on her approach to filmmaking, and on Heaven on Earth in particular, are revealing:

I really like to push the comfort zone of my audiences ... so there is room for them to imagine ... to fill in, to learn more about cultures. The difference between western and eastern philosophy, is that in the west, reality is based on what we see; in eastern philosophy, reality is not just what we see, but beyond it. My Indian philosophy has come to the fore, because reality in this film is beyond what Chand perceives.

Undoubtedly, Mehta's own experiences as an immigrant woman in Canada and her battles with the policies and apparatus of film production bureaucracy, as an independent filmmaker in this country, which have been chronicled extensively in newspaper and magazine articles and several film journals, have profoundly shaped her attitudes towards social structures and the challenges faced by immigrants, particularly immigrant women, who find themselves in vulnerable positions within the society they are struggling to become a part of (Saltzman, 2007). 


\section{Naficy states:}

Accented film authors are literally and figuratively everyday journeymen and journeywomen who are driven off or set free from their places of origin, by force or by choice, on agonizing quests that require displacements and emplacements so profound, personal, and transformative, as to shape not only the authors themselves and their films, but also the question of authorship. Any discussion of authorship in exile, needs to take into consideration not only the individuality, originality, and personality of unique individuals as expressive film authors, but also, and more important, their (dis)location as interstitial subjects within social formations and cinematic practices (Naficy, 2001, $34)$.

Ultimately, the film ends on a hopeful note as Chand, through the ordeal of the snake ritual which she survives, and is in fact triumphant, thereby proving her innocence and perhaps more importantly her strength and dignity as a person, finds the will to leave her husband and go out on her own. The ending is a reflection of Mehta's own philosophy as she expressed in an interview:

We need to understand the dark aspects of our lives, and it's naïve to think we don't have any when we all do. I try to show this through my movies, but then add to it my personal belief that no matter how much darkness, there is always hope.

Link to Case Study Film of Deepa Mehta's film Heaven On Earth.

https://www.youtube.com/watch? $v=S 0 R B$ wira $8 d Y \&$ feature $=$ youtu.be.. 


\section{Chapter Four \\ Risks / Responsibilities / A Way Forward}

While the issue of representation of diasporic communities of colour in screen/narrative media and their ability to express their "authentic voice" is complex with many factors affecting it, paramount amongst them being the role the "gatekeepers" in the industry play and issues of transparency and accountability, I believe the examination of legislative policies/frameworks and current government agency/industry practices as well as the case studies presented in this study shed some light on the root causes of barriers faced by individuals from these communities as well as possible remedies and strategies to engage both further examination and concrete action.

The issue of representation of members from diasporic communities of colour and other culturally diverse communities in the executive management positions which are responsible for commissioning programs in television broadcasting organizations will, in my opinion, have to be addressed if any real change is to take place. The "gatekeepers" in the industry-those who can "green light" a project and are responsible for controlling the content—are currently almost exclusively from mainstream communities.

At the moment there is no quantitative research data available on the numbers of racialized people working at senior management levels in the industry. As well, the Privacy Act is cited as preventing the gathering of information based on race and gender for employees and as a barrier to obtaining accurate information on which to create policies and practices that would address issues of representation of diasporic people of colour in the production of narrative programming on broadcast media and in film production in Canada. However, as there are in fact only a few of these positions in screen media in Canada, my observational analysis and through interviews with stakeholders in the industry indicates that there are no individuals 
from racialized communities in executive management positions at the $\mathrm{CBC}$ or at any mainstream broadcaster that is responsible for developing or commissioning the production of dramatic programs, i.e. being in a position to "green light" a production.

Government funding institutions (Telefilm Canada, Canadian Media Fund) also do not have any members of racialized groups who hold senior management positions in areas that are responsible for programming for prime-time broadcast or feature film production. This is surprising and troubling as it indicates that over three decades of diversity "policies" and special "initiatives" designed at improving representation in front of and behind the camera has had very little impact in increasing representation of racialized people in senior management positions in the television industries.

It is clear that if only very few narrative programs from diasporic people of colour are being commissioned, and only on a very occasional basis, then there will continue to be limited opportunities for other creative people from these communities, i.e. writers, performers, directors, et cetera to find meaningful work in the industry.

It is my contention that the experience of individuals such as Zarqua Nawaz, creator of the concept for Little Mosque in Prairie, and of Deepa Mehta, writer/director of the feature film Heaven on Earth, as outlined in the case studies, are instructive in how industry practices can affect the expression of "authentic voices" from diasporic communities of colour in screen media. In the case of Ms. Nawaz, it is apparent that despite the fact that the program was presented as the expression of her "authentic voice," the reality was she was increasingly marginalized from the creative process due to decisions made by the $\mathrm{CBC}$ management. As well, the key decision makers and creative personnel were not from the community that the primary characters were from, which had the result of story lines and character portrayals not being 
authentic. I believe that this in fact was a primary factor which led to the steady decline in the audience, which eventually resulted in the cancellation of the series. The primary financial beneficiaries from the production were also not from the community nor were there any longterm benefits to screen-media workers who are members of the Muslim community, the community that was at the core of the series.

In the case of Deepa Mehta and the production of Heaven on Earth, it is apparent that it was because of her international success with her previous film Water that she was able to finance the production of the film within the Canadian funding structures (Telefilm Canada, the National Film Board, and Canadian tax credits) and preserve her "authentic voice" without mediation from the financiers. She also felt this was a unique situation and that it was unlikely to be repeated again given the economic realities of the screen-media industry and its institutional practices and systemic barriers. It does raise the question of how likely are these same factors to be present for other screen-media creators of colour in order for them to be able to express their "authentic voice" without mediation.

Many of the screen media professionals of colour I interviewed felt that they had encountered a large degree of resistance to their projects as the people they were proposing their projects to have very little understanding of racialized communities or felt a need to include them in their programming other than as minor characters playing what were often stereotypical roles. A number broke down in tears during our interview while recounting their experiences of attempting to survive in the screen-media industry. Several stated bluntly that they were convinced that the barriers they encountered were based on their colour and race. A few of them said that despite the skills they had developed as producers, directors, and writers, many of them in their country of origin as well as through the "ethnic broadcasting" system in Canada, the 
institutionalized practices of the mainstream screen-media industry that they encountered were a result of racist and discriminatory practices that, despite stated policy goals of inclusion and celebrating cultural diversity by broadcasters and funding agencies, were deeply embedded in the culture of the organizations. A number had found the struggle too great and had left the industry to find work in other parts of the economy in order to survive.

The recent consolidation in the television industries has also reduced the number of individuals in key decision-making positions who are responsible for commissioning or "green lighting" programs, narrowing the opportunities for producers of narrative programming across the board and particularly for producers from diasporic communities of colour.

The risk of not addressing this issue is that it will continue to have a detrimental effect on both the quantitative and qualitative, representation of cultural diversity on our screens particularly in the area of narrative programming. Given that due to the nature of television and feature film production and the fact that a large portion of the funding comes from government sources and the fact that there are no people from racialized communities in key creative decision making roles, I believe the barriers for unmediated diasporic voices of colour to be heard sing their "authentic voice" on Canadian television are significant. If one accepts the reasoning that people generally make decisions based on their own tastes and experience, it is unlikely that without having members of racialized communities in creative decision-making positions, which influence what we see on our screens, at the senior management level, there will be any meaningful change in this situation in the short term. The link between the people who commission programs and the type of programming that is commissioned is clear. I believe that the evidence presented in this study as well as other related studies indicates that systemic 
problems in hiring are not being addressed despite the existence of "diversity policies" and" special initiatives" employed from time to time by broadcasters.

It appears that there is no one at the key agencies responsible for formulating policies and funding programming, be it Canadian Heritage, the CRTC, Crown Corporation funding agencies, Telefilm Canada Media Fund, or broadcasters, beyond acknowledging a problem exists and instituting occasional training programs, mentorships, and short-term internships and "special programs," who are empowered to, take the steps necessary to ensure that the systemic barriers that exist for racialized screen media workers, are dismantled and meaningful, consistent, and measurable change takes place. As a result, I believe the changes needed to allow full participation for people of colour from diasporic communities and other marginalized groups will be extremely slow in coming.

Many of the initiatives currently in place, i.e. mentorships, workshops, training programs, and limited-term funding programs have been attempted for over the past three decades with very little meaningful change taking place. I have had the opportunity to observe this first hand through my various positions working at the $\mathrm{CBC}$, as an independent producer, and as a researcher and consultant in the screen-media industry. In order to dismantle the institutional barriers that are responsible for creating what have become "networks of exclusion" in the screen-media industry for diasporic people of colour in Canada, specific requirements for these institutions that can be measured and monitored need to be put in place.

In my interviews with members of senior management at the government agencies responsible for formulating policies and regulating the industry and at the $\mathrm{CBC}$, I felt there was an understanding that there were significant issues involving representation, equity, and social justice in the screen-media industry and a desire for change. However, it is my feeling that due to 
other pressing priorities in their positions and with no specific requirements and incentives to remedy the systemic barriers for diasporic people of colour to participate fully in the industry, given the complexities of both instituting the changes required and the financing/production process, that it is unlikely any substantive improvement would take place in the immediate future.

One of the risks, apart from both the moral, ethical, and employment equity implications, of the CRTC and media institutions not having specific requirements to fulfill the mandates as set out in the Broadcast Act, the Multiculturalism Act and Employment Equity Act with regards to the accurate reflection of the diversity of Canadian society in all aspects of screen media in Canada is that the resulting marginalization and exclusion of members of diasporic communities of colour, working in the screen, will inevitably result in loss of a sense of belonging and ultimately disassociation from mainstream Canadian culture by members of these communities, who are increasingly forming a larger part of Canadian society.

Rapid developments in digital technology have made television programming on a variety of digital platforms from "home" countries increasingly available and affordable, which allows new immigrants and second- and third-generation Canadians from minority communities to essentially "bypass" Canadian media. If Canadian screen media does not reflect their presence except in stereotypical portrayals (Fleras and Kunz 2001) and their hopes and aspirations, why watch it? With programming now easily available from their home countries via the Internet satellite and Canadian-based "third-language" TV channels, there is no incentive to watch Canadian programming. This has important implications for the future of Canada as a nation, and our sense of identity and belonging, living in a multi-racial, multicultural society. 
Unfortunately, as sections of this study have hopefully illustrated, the response of both federal government cultural departments and agencies and private sector film production and broadcasting institutions to the requirements set out in the Multiculturalism Act and to the Employment Equity Act has been generally inconsistent and ineffective. It has been articulated as a mandate and a corporate commitment but very few organizations have taken specific measures to ensure adherence to both the letter and the spirit of the law (Fleras 2010). A review of the annual report on the operation of Multiculturalism Act and the Ministry of Heritage reports for 2015 to 2016 made virtually no mention of the issue of the reflection of people of colour or "visible minorities" in screen media in Canada as a priority other than to report on a few events that were held by agencies and organizations governed by the Multiculturalism Act, the Broadcast Act, and Employment Equity Act, that reflected the "diversity of Canada" as well as stating their ongoing commitment to equity in all areas of cultural expression.

Without equitable access to the resources and opportunities in this key sector of society, despite the opportunities they are entitled to under government policies of Multiculturalism and Employment Equity, members of racialized communities cannot fully participate as citizens using their "authentic voices", or see themselves reflected in an important public arena in our increasingly diverse society.

This was borne out by many of the participants in the Roundtable on Cultural Diversity in the Toronto Screen Media Production Industry held at Ryerson University in Toronto on September 2011. In its Report and Action Plan it stated:

Considerable gaps exist between stated policies with regards to Canadian multiculturalism and the reality of inclusion and cultural diversity representation in the production of film and mainstream television 
programming. Consequently, the screen entertainment available to Canadians does not represent Canada's cultural diversity. The range of economic opportunities available to visible minority producers is much narrower than the range of opportunities available to others. The extremely low level of inclusion of visible minority producers in the film and television production industry is due to systematic barriers.... Employment equity legislation does not provide a direct remedy to economic marginalization of visible minorities in the screen production industry because most of the economic relationships are based on contracting, not on salaried employment. Third language or "ethnic channels" which are aimed at specific ethno-cultural groups, produce very little original programming, particularly in the area of drama, including comedy and variety shows.

The Report and Action Plan made several recommendations, which included:

A CRTC license for a Category A channel (mandatory carriage as a basic service on cable and satellite distribution platforms -similar to APTN the Aboriginal People's Network)) with a specific mandate for broadcasting original prime time Canadian dramatic programming created by visible minority media producers should be given serious consideration by the CRTC and industry stakeholders. The use of film \& television tax production incentives to improve economic opportunities for minorityowned production companies should be considered. 
As referenced earlier, since the creation of Aboriginal Peoples Network (APTN), which received its national broadcasting license in 1999, the requirements that programming commissioned from independent producers be produced by companies that were owned by people from those communities has significantly increased opportunities for Aboriginal producers and screen media storytellers.

Is there a way forward? Based on my research and interviews with key industry policy makers and creative workers from diasporic communities of colour, many of whom expressed a strong commitment to attempting to find measures to remedy the inequities of representation by diasporic people of colour in film and television in Canada, and the conclusions I have drawn from the case studies of the television series Little Mosque on the Prairie and the feature film Heaven on Earth, I believe that while there is no "easy fix" for issues that exist because of systemic barriers and institutionalized practices that marginalize and discriminate against racialized communities, there are practical steps that can and should be taken.

In my opinion, the most effective way to achieve the goals of equitable representation in the area of prime-time narrative programming is for the federal government, where it has jurisdiction and responsibilities in this area through its current legislation and federally constituted agencies such as Telefilm Canada, the Canada Media Fund, and the $\mathrm{CBC}$, to require minimum amounts of spending based on demographic realities, on programs that are created by members of racialized communities.

As well, such programs should be produced by companies that are majority owned by members of these communities as in the requirements by APTN. Several individuals I interviewed from the diasporic communities of colour as well as senior managers in the industry and funding agencies suggested as an initial measure, a formula of $20 \%$ of funds spent on 
scripted programming, including license fees and investment funds from Crown corporations, be allocated to programs in which two out of three of the key creative positions (producer, writer, director) come from racialized communities and that the production company be majority owned by members of that community for a trail period of five years, with an evaluation process undertaken in year 4 of the program to measure gains and make specific recommendations for ongoing activities of the program. Additionally, all independent production companies receiving public funds would be required to institute training/development/internship programs in productions commissioned by Canadian broadcasters and which received investment and support from Government funding agencies.

Establishing minimum expenditure requirements for programs will result in increased opportunities for diasporic people of colour working in screen-based media in Canada across the board including producers, directors, writers and performers. This may undoubtedly be a policy that will be controversial and not immediately be embraced by all sectors of the industry or the public given current negative sentiments in some areas of society towards 'affirmative action' and Equity programs.

It is my opinion that the leadership to initiate the research to examine the specifics of how a program such as this could work should come from the Minister of Heritage with strong representations from members of racialized communities working in screen media industries and their community organizations, academics, social justice organizations, and members of funding agencies and broadcasters and screen media unions and organizations representing screen media professionals.

The Aboriginal Peoples Television Network's success using these requirements is an encouraging model that can be learnt from and implemented to serve the needs of diasporic 
communities of colour and thereby enrich Canadian screen storytelling and ensure more equitable opportunities for all Canadians, thereby enriching the country as a whole.

Implementing specific measures with appropriate monitoring and measurable outcomes I believe will begin to address the pressing issues of inequitable representation of racialized communities, and transparency and accountability issues in screen based media in Canada and fulfill the requirements of both the spirit and the letter of the legislative frameworks established by the Government of Canada to ensure full participation and equitable access to the resources and opportunities available to all Canadians It will as well as strengthen the fabric of our multicultural society and enrich the lives of all of its citizens. 


\section{Works Cited and Consulted}

Bannerji, Himani. "On the Dark Side of the Nation Politics of Multiculturalism and the State of "Canada," Journal of Canadian Studies 31, no. 3, pp. 103-128.

Canadian Media Producers Association Report. Profile 2016

http://cmpa.ca/sites/default/files/documents/industryinformation/profile/Profile $\% 2$ 02016\%20-\%20EN.pdf Accessed Sept 252017.

Conway, Kyle. (2017) Little Mosque on the Prairie and the Paradoxes of Cultural Translation, University of Toronto Press.

Bernstein, Deborah, Sally Cato, Anton Leo, and Carol White. Personal interview.

Darling, Mary, Rebecca Schechter, and Sadiya Durani. Interview. http://en.wikipedia.org/wiki/Little_Mosque_on the Prairie. Accessed Dec. 19, 2013.

Deverall. Rita Playback Magazine December 152008.

Ellis, TEAdams, AP Bochner. (2011). Autoethnography: an Overview

Fleras, A, and J. Kunz. (2001). Media and Minorities: Representing Diversity in a Multicultural Canada. Toronto: Thompson Educational Publishing Inc.

Fleras, A. (1995). "Please Adjust Your Set: Media and Minorities in a Multicultural Society." Communications in Canadian Society, 4th ed., Toronto: Nelson Canada.

Frantz Fanon, Richard Philcox (2008) Black Skin, White Masks Grove Press New York

Fraser, Mathew. Free-For-All: The Struggle for Dominance on the Digital Frontier.1999. Stoddart. Toronto.

Galabuzi, Grace-Edward. (2006). Canada Economic Apartheid .The Social Exclusion of racialized groups in the new Century. Canadian Scholars Press.

Hall, Stuart (1981). "The Whites of their Eyes: Racist Ideologies and the Media." In G. Bridges and. Brunt (Eds.). Silver Linings: Some Strategies for the Eighties. London: Lawrence and Wishart.

Henshaw, Jim. http://the-legion-of-decency.blogspot.ca/2010/01/unbearable-whiteness- ofbeing-on.html accessed . Dec.18, 2013.

Hamilton, David. Personal interview. 
Levitin, Jacqueline, Judith Plessis, Valerie Raoul, (2003) An Introduction to Deepa Mehta: Making Films in Canada and India. Women Filmmakers: Refocusing. UBC Press.

Mahtani, M. (2001). Representing minorities: Canadian media and minority identities. Canadian Ethnic Studies.

McLuhan, Marshal. (1964). Understanding Media: the Extensions of Man. Toronto: McGraw-Hill.

Mehta, Deepa. Interviewed by Raj Girin. http://www.openchest.com/oc-inprint/producer-director-scriptwriter-deepa-mehta/ Retrieved December 20, 2011.

Mehta, Deepa. Personal interview.

Murray, Catherine. (2005). "Silent on the Set: Monitoring Cultural Diversity and Race in Canadian TV Drama in New Thoughts on Intercultural Communication, Wuhan University Press. pp. 131-138.

Naficy, Hamid. (2001) An Accented Cinema: Exilic and Diasporic Filmmaking. Princeton. Princeton University Press.

Nesbitt-Larking, Paul. Politics, Society and the Media. 2007. $2^{\text {nd }}$ Edition. Broadview $\quad$ Press. Peterborough, Canada.

Reitz, Jeffrey G., Bannerjee, Rupa. (2006). Racial Inequality, Social Cohesion, and Policy Issues in Canada. University of Toronto. October.

Roundtable on Cultural Diversity and Action Plan 2012. RTA School of Media. Ryerson University.

Safran William, Diasporas in Modern Societies: Myths of Homeland and Return (1991).

Said, Edward. W. 1994 "Intellectual Exile: Expatriates and Marginals" In Representations of the Intellectual: the 1993 Reith Lectures New York Vintage.

Saltzman, Devyani.(2007) Shooting Water. Toronto. Key Porter Books.

Shohat, Ella, and Robert Stam, Editors. 2003. Multiculturalism, Postcoloniality and Transnational Media. Rutgers.

Shohat Ella, and Robert Stam. (1994). Unthinking Eurocentrism: Multiculturalism and the Media London Routledge.

Siddiqui, H. (2001 April 22). Media out of touch with new pluralistic Canada. Toronto Star.

Spivak, G. C. (1987). In other worlds; essays in cultural politics London. Methuen. 
Stursberg, Richard. (2012) Tower of Babel: Sins Secrets and Successes Inside the CBC.. Douglas and McIntyre. Toronto.

Sukhmani, Khorana. (2011) Locations: The Situated Influences of Deepa Mehta's Film Trilogy. Imagining Home: Migrants and the Search for a New Belonging. Edited by Diana Glenn, Eric Bouvet, Sonia Floriani. Wakefield Press.

Zielinski, Siegfried.(1999) Vanishing Point Television? Audiovisions: Cinema and Television as Entr'actes of in History. Amsterdam: University of Amsterdam.. 189-218.

https://yvesengler.com/2013/12/10/our-shame-canada-supported-apartheid-south-africa/]

Roundtable on Cultural Diversity in the Toronto Screen Media Production Industry Report and Action Plan. May 31, 2012. Charles H. Davis, Ph.D. RTA School of Media. Ryerson University.

Canadian Screenwriter Magazine. Summer. 2002. Vol. 9. No. 3. pgs. 8 -11.

EPK Heaven on Earth 2008.

http://cws.journals.yorku.ca/index.php/cws/article/viewFile/7638/6769

review of dark side of the nation by Himani Bannerji .

\section{Policy Documents}

Broadcastinging Act. (1991). - http://www.canlii.org/en/ca/laws/stat/sc-1991-c-11/latest/sc-

Broadcasting Public Notice CRTC 2005-1 2005-1-1 Ottawa, 7 January 2005

Canadian Multi-Culturalism Act (1971)

Canadian Charter of Rights and Freedoms (1982)

Canada One Qualitative Exploratory Study March, 2006 Solutions Research Group. Unpublished

Canada One TV CRTC Hearing. (2006). Transcrit

http://www.crtc.gc.ca/eng/transcripts/2007/tb0327.htm

Ethnic broadcasting policy Public Notice CRTC 1999-117 Ottawa, 16 July 1999)

Employment Equity Act (1995) Section 2Annual Report on the Operation of the

Canadian Multiculturalism Act 2015-2016Diversity and Inclusion in Action@Her Majesty the Queen in Right of Canada, (2017). 
Catalogue No. Ci95-1E-PDF

ISSN 1497-7400

Privacy Act Government of Canada R.S.C., 1985, c. P-21

https://www.canada.ca/en/canadian-heritage/campaigns/creative-canada/framework.html accessed Oct 312017

\section{List of Interviews}

\section{Chapter One}

Drew Olsen. Director, Marketplace and Legislative Policy, Broadcasting and Digital

Communications branch, Canadian Heritage.

Martin Jourdeais. Director, Content Policy, Broadcast Policy and Digital Communications

branch Canadian Heritage.

Lynn Foran. Manager Film \& Video Policy and Programs, Cultural Industries Broadcast Policy

and Digital Communications branch Canadian Heritage.

Pierre Marc Perreault. Manager, English television Applications. Canadian Radio-television and Telecommunications Commission (CRTC).

Valerie Creighton. President and CEO Canadian Media Fund (CMF).

Stéphane Cardin. Vice President, Industry and Public Affairs. Canadian Media Fund. (CMF).

Carolle Brabant. Executive Director. Telefilm Canada.

Francesca Accinelli. Director, National Promotion and Communications Telefilm Canada.

Chapter Two

Sally Cato. General Manager of Programming. CBC English Television. Former executive in charge of scripted programming CBC English network.

Heather Boyce Director Accessibility, Inclusion \& Diversity CBC English network.

Deborah Bernstein former Head of scripted programming CBC English network.

Anton Leo former Head of Comedy programming CBC English network.

Mary Darling. Executive Producer. Little Mosque on the Prairie. WestWind Pictures.

Clark Donnelly. Executive Producer Little Mosque on the Prairie WestWind Pictures.

Rebecca Schecter. Writer/Showrunner Little Mosque on the Prairie.

Sadia Durani. writer/consultant Little Mosque on the Prairie.

Chapter Three

Deepa Mehta. Writer/Director Heaven on Earth Hamilton Mehta Productions.

David Hamilton Executive Producer Heaven on Earth Hamilton Mehta Productions.

Shahram Tabe founder co director Diaspora Film Festival.

Diasporic screen-media artists

Jennifer Hollness Producer Hungry Eyes Pictures.

Amos Adetuyi Producer Circle Blue Media.

Cyrus Sunder Singh, Producer/Director. Salaam Shalom Productions.

Karen King Producer. Former Television executive Global television Toronto One TV.

George Chu Former Television executive CTV The Comedy Channel. 
Vance Chapman. Writer.

Bobby del Rio. Writer/Producer.

Damon D'Olivera. Producer. Conquering Lion Productions.

Tonya Williams. Actress/Producer founder Reelworld Film Festival.

Trey Anthony. Playwright/ Actor /Producer Trey Anthony Studios.

Link to Case Study Film of Deepa Mehta's film Heaven On Earth.

https: $/ / w w w . y o u t u b e . c o m / w a t c h ? v=S O R B w i r a 8 d Y \&$ feature $=$ youtu.be 